\title{
Briófitas da Reserva Particular do Patrimônio Natural da Serra do Caraça, Estado de Minas Gerais, Brasil
}

\author{
- Dimas Marchi do Carmo ${ }^{1,2}$, Jéssica Soares de Lima ${ }^{1}$, Marcela Inácio da Silva ${ }^{1}$, \\ Leandro de Almeida Amélio ${ }^{1}$ e Denilson Fernandes Peralta ${ }^{1}$
}

Recebido: 22.03.2018; aceito: 6.07.2018

\begin{abstract}
Bryophytes in the Reserva Particular do Patrimônio Natural da Serra do Caraça, Minas Gerais State, Brazil). The Reserva Particular do Patrimônio Natural da Serra do Caraça is located in the orographic complex of the Espinhaço Range and is characterized as a transition zone between two important Brazilian phytogeographical domains, the Atlantic Forest and the Cerrado. It is composed of different types of plant formations and presents, predominantly, the rocky fields. In the Reserva Particular do Patrimônio Natural da Serra do Caraça, we recorded 439 bryophyte species (238 mosses, 199 liverworts, and two hornworts), 74 (17\%) Brazilian endemic species and 80 (18\%) new records for Minas Gerais State. The Lejeuneaceae was the richest liverworts family, with 75 species, while Sphagnaceae showed the greatest richness for mosses, with 29 species. Most of the species found have a moderate distribution to the country and are Neotropical.

Keywords: Atlantic Forest, Cerrado, hornworts, liverworts, mosses
\end{abstract}

RESUMO - (Briófitas da Reserva Particular do Patrimônio Natural da Serra do Caraça, Estado de Minas Gerais, Brasil). A Reserva Particular do Patrimônio Natural (RPPN) da Serra do Caraça está localizada no complexo orográfico da Cadeia do Espinhaço e caracteriza-se como uma área de transição entre dois importantes domínios fitogeográficos brasileiros, a Mata Atlântica e o Cerrado. Essa Reserva é composta por diferentes tipos de formações vegetais e apresenta, predominantemente, os campos rupestres. Na Reserva Particular do Patrimônio Natural da Serra do Caraça foram encontradas 439 espécies de briófitas (238 musgos, 199 hepáticas e dois antóceros), 74 (17\%) espécies endêmicas brasileiras e 80 (18\%) novos registros para o Estado de Minas Gerais. A família de hepáticas Lejeuneaceae foi a mais rica, com 75 espécies, enquanto Sphagnaceae apresentou maior riqueza para os musgos, com 29 espécies. A maioria das espécies encontradas apresenta uma distribuição moderada para o país e são neotropicais.

Palavras-chave: antóceros, Cerrado, hepáticas, Mata Atlântica, musgos

\section{Introdução}

A Reserva Particular do Patrimônio Natural (RPPN) da Serra do Caraça localiza-se entre as formações rochosas componentes do sistema orográfico da Cadeia do Espinhaço (Vasconcelos 2011), o qual inicialmente era conhecido por ser uma importante fonte de riquezas minerais e de pedras preciosas e, atualmente com o advento dos estudos biológicos, se tornou um importante centro de endemismo de espécies da flora e da fauna para a região neotropical (Giulietti et al. 1997; Rapini et al. 2008).

A Cadeia do Espinhaço é uma macrorregião que apresenta uma extensão territorial entre $6.000-7.000$ $\mathrm{km}^{2}$ e é composta por um mosaico de vegetações, sendo sua área predominantemente ocupada pelos campos rupestres que abrange desde o sul do Estado de Minas Gerais, com início nas proximidades de Belo Horizonte, penetra no Estado da Bahia pela região da Chapada Diamantina e se estende até o norte do mesmo, terminado próximo ao município de Juazeiro (Melo 2000). Essa extensão territorial, junto com as diferentes formações vegetais, proporciona condições favoráveis para uma elevada riqueza de espécies e de surgimentos de centros de endemismo (Giulietti et al. 1987, Conceição et al. 2005, Versieux et al. 2008, Rapini et al. 2008).

Os estudos de briófitas existentes na Cadeia do Espinhaço são muito escassos se comparados

1. Instituto de Botânica, Núcleo de Pesquisa em Briologia, Avenida Miguel Estéfano, 3687, 04301-902, São Paulo, SP, Brasil

2. Autor para correspondência: dimas.botanica@gmail.com 
com os de outros grupos vegetais, o que revela uma necessidade de aumentar as pesquisas nessa importante região (Costa et al. 2011). Alguns exemplos que podemos destacar são os estudos realizados no Estado da Bahia nos trabalhos de Bastos et al. (2000), Valente et al. (2011), Valente et al. (2013) e Valente et al. (2017) para o conhecimento da distribuição geográfica de briófitas entre as diferentes formações vegetais presentes na Chapada Diamantina; enquanto no Estado de Minas Gerais, são encontrados os de Yano \& Carvalho (1995) na Serra da Piedade, Yano \& Peralta (2009) para a Serra de Grão-Mogol, Yano \& Peralta (2011a) na Serra de São José, LuiziPonzo et al. (2013) no Parque Estadual de Ibitipoca, Yano \& Peralta (2011b) e Souza \& Câmara (2015) na Serra do Cipó e, recentemente, Carmo \& Peralta (2016) e Carmo \& Peralta (2017) no Parque Nacional da Serra da Canastra. Como resultado desses e de outros trabalhos realizados no Estado de Minas Gerais, temos atualmente um total de 773 espécies de briófitas registradas para o Estado de Minas Gerais como um todo, o que representa aproximadamente metade da riqueza de briófitas relatadas no Brasil (Flora do Brasil 2020).

Até o momento não foi realizado nenhum levantamento florístico das espécies de briófitas existentes na região da Serra do Caraça, a qual abrange o Estado de Minas Gerais e a Cadeia do Espinhaço, o que realça a necessidade da realização desse estudo uma vez que os levantamentos florísticos são trabalhos de base de conhecimento para outras áreas da ciência. Sendo assim, esse trabalho tem como objetivo apresentar a brioflora das espécies ocorrentes na RPPN da Serra do Caraça com o intuito de ressaltar a contribuição das áreas de conservação para a manutenção das espécies de briófitas e oferecer informações sobre a sua distribuição geográfica brasileira e mundial, bem como conhecer os domínios fitogeográficos que as espécies encontradas na RPPN da Serra do Caraça ocupam.

\section{Material e métodos}

Área de Estudo - A Cadeia do Espinhaço é constituída principalmente por campos rupestres, mas também pode apresentar outras formações vegetais como as matas de galeria, capões de florestas montanas, floresta estacional semidecidual, campos de altitude, campos úmidos, campos limpos, campos sujos, matas de encosta, cerrado sensu stricto e áreas de cachoeiras (Giulietti \& Pirani 1988, Giulietti et al. 1997, Versieux et al. 2008, Couto Júnior et al. 2010, Carmo \& Peralta 2016).

A Reserva Particular do Patrimônio Natural da Serra do Caraça abrange os municípios de Catas Altas e Santa Bárbara, aproximadamente a $120 \mathrm{~km}$ de Belo Horizonte. O clima segundo a classificação do sistema de Köppen é do tipo $\mathrm{Cwb}$, ou seja, é classificado como subtropical de altitude, também chamado de mesotérmico (temperado chuvoso) onde a temperatura média na época mais quente é inferior a $22{ }^{\circ} \mathrm{C}$ e no inverno podem até chegar a $0{ }^{\circ} \mathrm{C}$ com geadas mais intensas (Ferreira et al. 1977). Possui ca. de 11.233 ha. com seu ponto mais alto no chamado Pico do Sol, com $2107 \mathrm{~m}$ e sua sede se localiza a $1240 \mathrm{~m}$ de altitude. As principais fitofisionomias encontradas na RPPN da Serra do Caraça são os campos rupestres, campos de altitudes, capoeiras, floresta estacional semidecidual, matas de galerias, matas ciliares e matas nebulares (Morais \& Lombardi 2006, Vasconcelos 2011).

Amostragem - Foram realizadas expedições de coletas na área da RPPN da Serra do Caraça durante os anos de 2008 e 2016 e análises de materiais depositados no herbário do Instituto de Botânica "Maria Eneyda Pacheco Kauffman Fidalgo" (SP). Foram estudadas 1696 amostras (exsicatas) provenientes da RPPN da Serra do Caraça. As coletas foram realizadas por meio de caminhadas livres e em todos os tipos de substratos disponíveis que as briófitas pudessem colonizar. A metodologia para a coleta, herborização e preservação do material seguiu Gradstein et al. (2001) e todo o material obtido nas coletas está depositado no herbário SP.

As referências usadas para a identificação das espécies foram Frahm (1991), Sharp et al. (1994), Buck (1998), Gradstein et al. (2001), Visnadi (2002), Gradstein \& Costa (2003), Câmara \& Costa (2006), Vaz \& Costa (2006a, b) Visnadi (2006), Câmara (2008a, b), Ballejos \& Bastos (2009), Yano \& Peralta (2009), Yano \& Peralta (2011b) e Bordin \& Yano (2013).

Os sistemas de classificação adotados foram variados, uma vez que existem certos grupos de briófitas em que a classificação foi modificada e atualizada conforme o progresso dos estudos taxonômicos. Sendo assim, os sistemas utilizados foram baseados em Kruijer (2002), Crandall-Stotler et al. (2009), Frey \& Stech (2009), Goffinet et al. (2009), Renzaglia et al. (2009), Costa et al. (2011), Söderström et al. (2013a, b), Gradstein (2015), Gradstein \& Ilkiu-Borges (2015) e Carvalho-Silva et al. (2017). 
As espécies encontradas estão organizadas em uma tabela por ordem alfabética, divisão, família, gênero e espécie (tabela 1). É apresentado um padrão de distribuição geográfica brasileira das espécies discriminada em ampla, moderada e rara conforme a metodologia utilizada em Valente \& Pôrto (2006), bem como a distribuição mundial e dos domínios fitogeográficos brasileiros que as briófitas ocupam conforme Gradstein \& Costa (2003), Yano (2008), Forzza et al. (2010), Costa et al. (2011), Valente et al . (2013), Carmo \& Peralta (2016) e Flora do Brasil 2020 .

\section{Resultados e Discussão}

Foram encontradas 439 espécies distribuídas em 62 famílias e com 80 novas ocorrências de briófitas para o Estado de Minas Gerais. A divisão dos musgos apresentou 36 famílias e 238 espécies, as hepáticas resultaram em 24 famílias e 199 espécies, enquanto para os antóceros foram encontradas apenas duas espécies representadas em duas famílias diferentes (tabela 1). Esse número de espécies representa 57\% das briófitas registradas para o Estado de Minas Gerais, 28\% das registradas para o Brasil e $11 \%$ das encontradas para a América tropical (Gradstein et al. 2001, Flora do Brasil 2020) (tabela 2).

A família Lejeuneaceae foi a que apresentou a maior riqueza de espécies na RPPN da Serra do Caraça, com 75 espécies (17\%). O número de espécies de musgos (238 espécies) foi superior ao de hepáticas (199 espécies), enquanto para os antóceros apenas duas espécies foram encontradas (tabela 1). Entre os musgos, a família Sphagnaceae foi a que obteve maior riqueza, com 29 espécies encontradas, sendo seguida pelas famílias Leucobryaceae (26 espécies), Sematophyllaceae (24 espécies) e Bryaceae (18 espécies) (figura 1). Na divisão das hepáticas as famílias Lejeuneaceae (75 espécies), Lepidoziaceae (20 espécies), Plagiochilaceae (15 espécies) e Frullaniaceae (13 espécies) estão entre as mais ricas (figura 2). Foram encontradas 80 novas ocorrências (18\%) para o Estado de Minas Gerais e 74 espécies (17\%) foram consideradas endêmicas para o Brasil (tabela 1).

Sphagnaceae pode ser considerada uma importante família entre a divisão dos musgos para a RPPN da Serra do Caraça, não apenas pelo número de espécies encontradas, mas também pela sua representatividade no número de espécies endêmicas e de novas ocorrências (tabela 1). A família

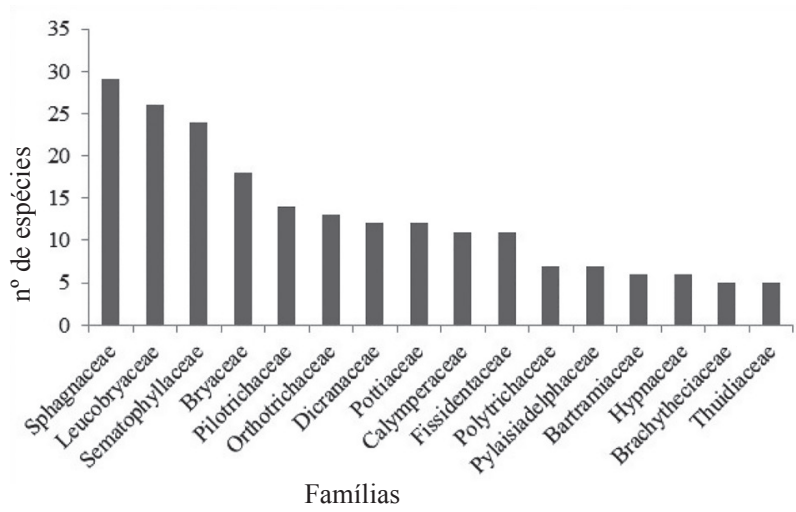

Figura 1. Representação gráfica da riqueza de musgos (Bryophyta) incluindo famílias com cinco ou mais espécies.

Figure 1. Graphic representation of the moss richness (Bryophyta) including those families with five or more species.

apresentou 18 espécies endêmicas do Brasil (24\%) e sete novas ocorrências para o Estado de Minas Gerais (9\%) (tabela 1). Além disso, a espécie Sphagnum platyphylloideum Warnst. até então era conhecida para a região do Caraça apenas pelo material tipo coletado há mais de 100 anos e, com esse trabalho, essa espécie pôde ser recoletada e desconsiderada de uma possível situação de extinção. As espécies de Sphagnaceae normalmente ocorrem próximas de cursos d'água (Schofield 1985), no entanto, ela também pode ser encontrada na Serra do Caraça em superfícies extremamente secas, como rochas e solos expostos, assim como foi observado em outras áreas de campos rupestres de Minas Gerais, como na Serra da Canastra (Carmo \& Peralta 2016, Carmo \& Peralta 2017).

No Brasil são relacionadas aproximadamente 295 espécies de Lejeuneaceae distribuídas em 54

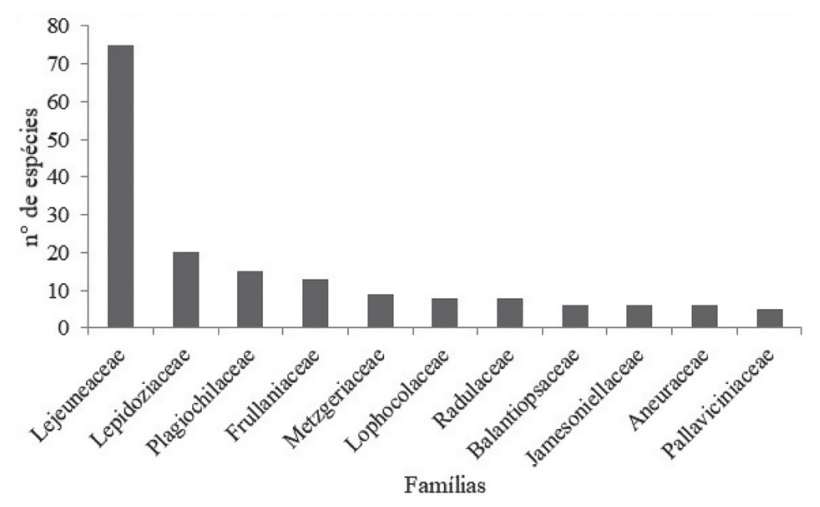

Figura 2. Representação gráfica da riqueza de hepáticas (Marchantiophyta) incluindo famílias com cinco ou mais espécies.

Figure 2. Graphic representation of the liverwort richness (Marchantiophyta) including those families with five or more species. 


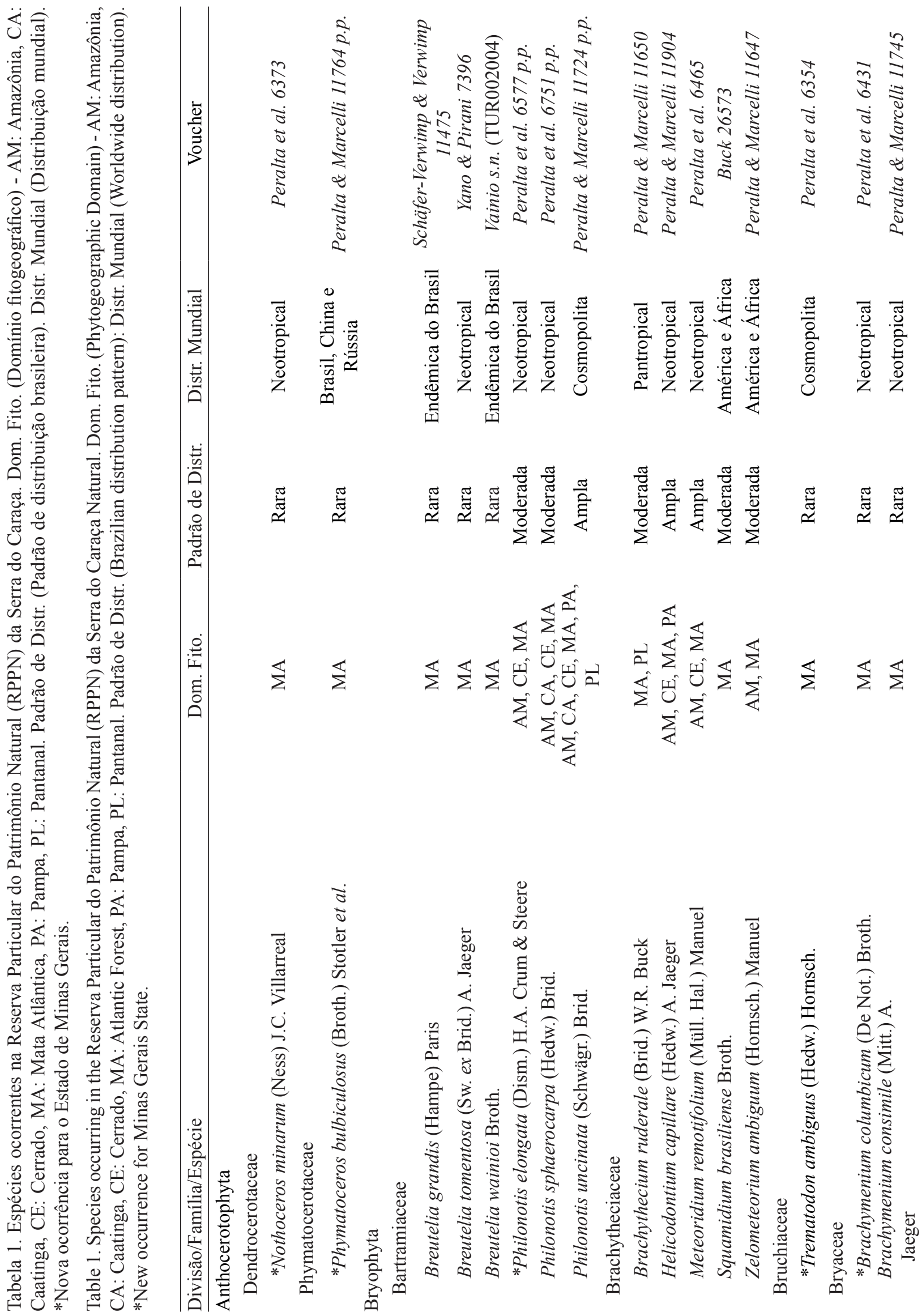




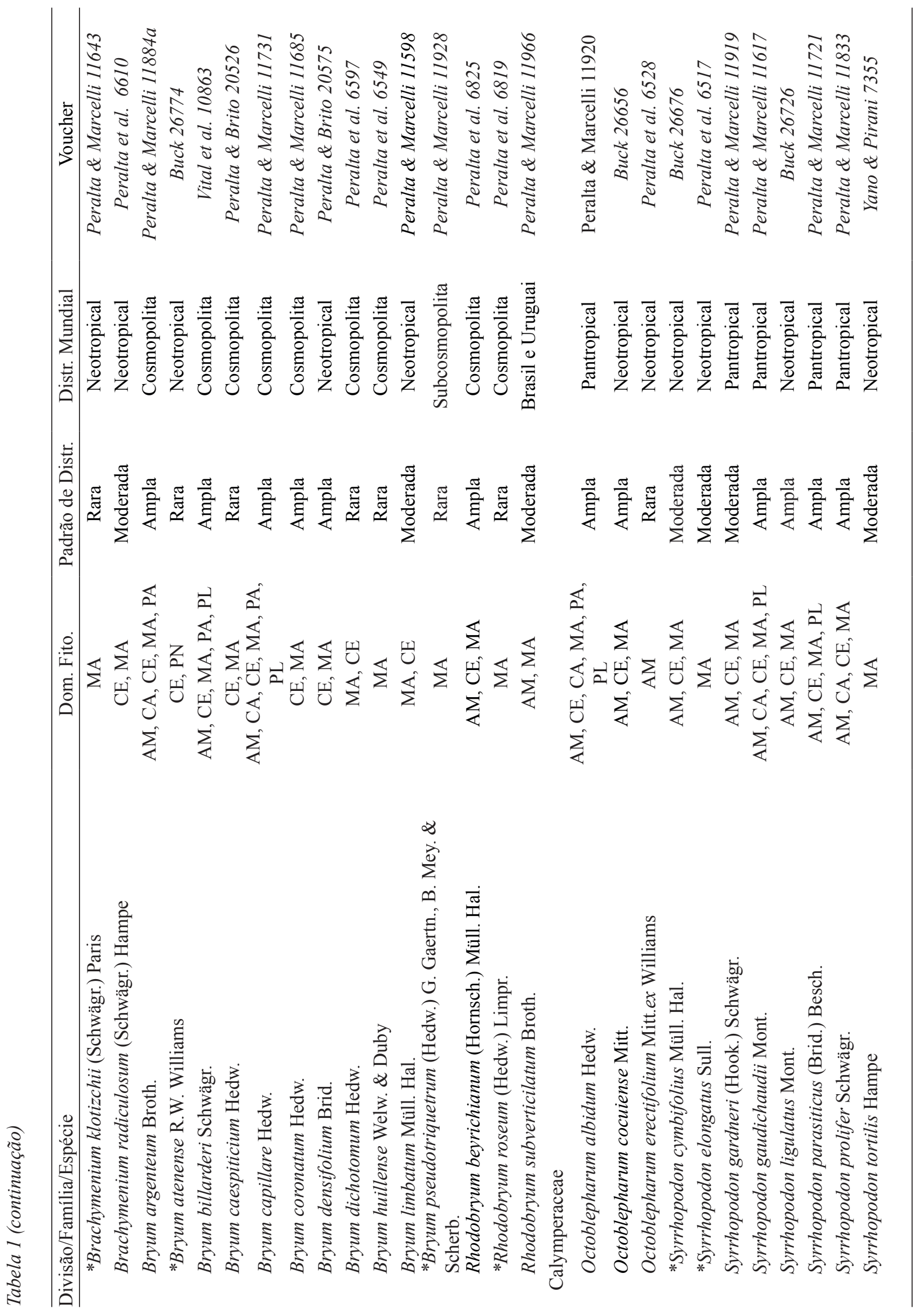




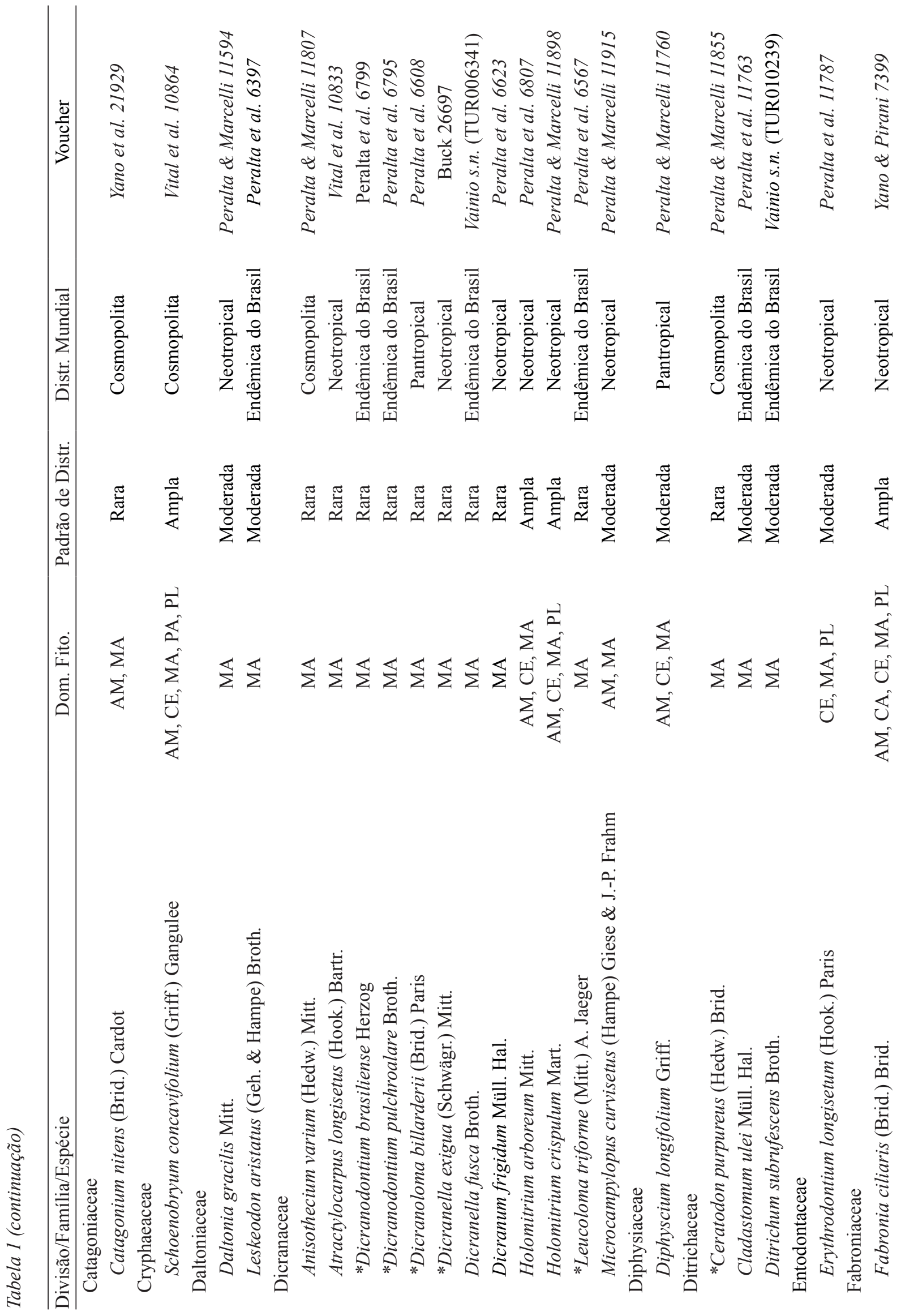




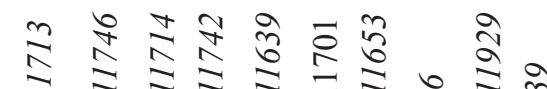

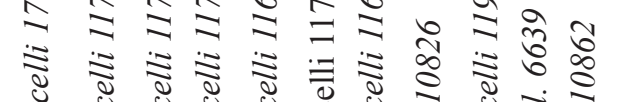

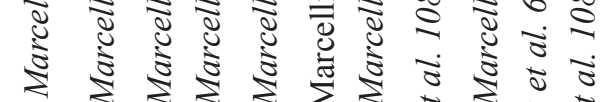

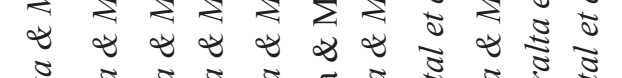

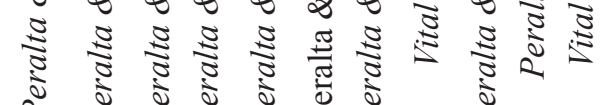

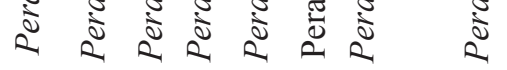

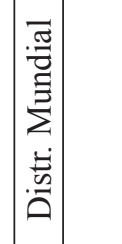

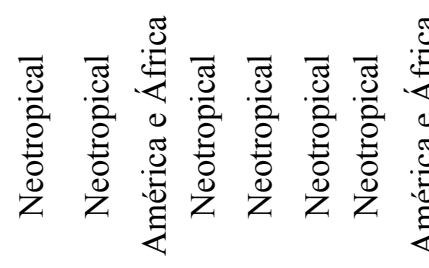

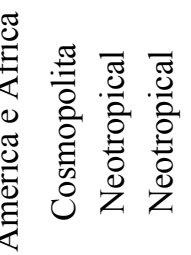

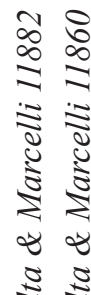

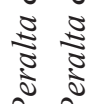

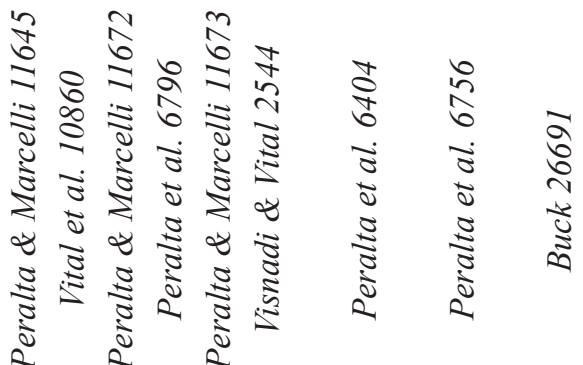

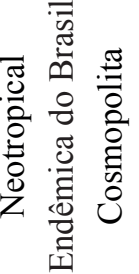

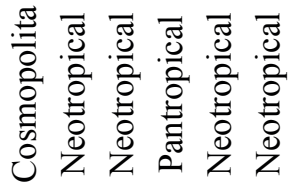

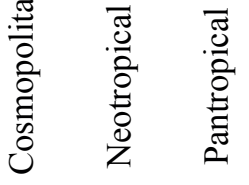

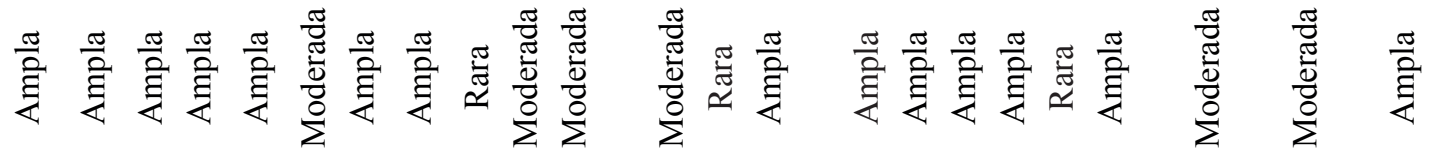

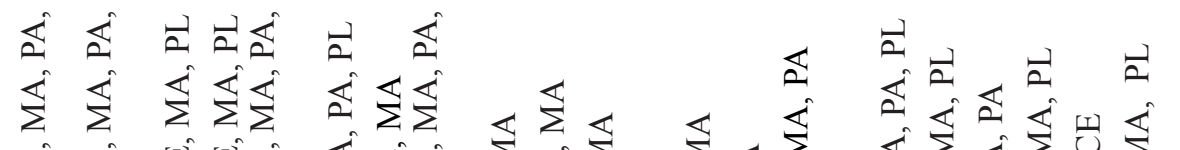

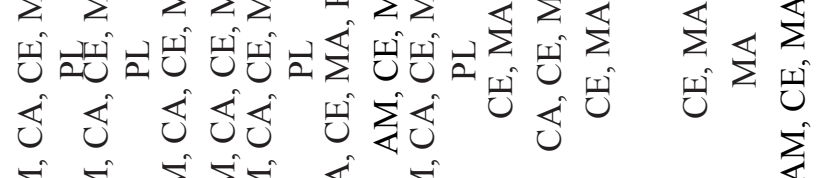

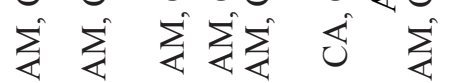

$\sum_{i}^{+}$ $\sum_{i} \sum_{i} \sum_{i}$

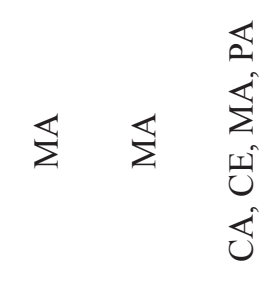

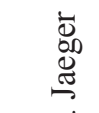

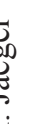

㐫

-

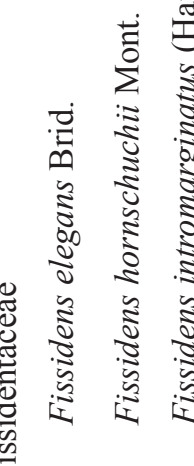

E $\quad$ क्ष

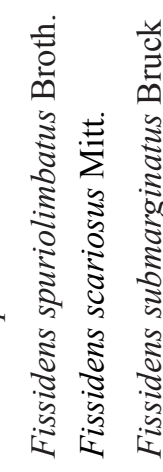

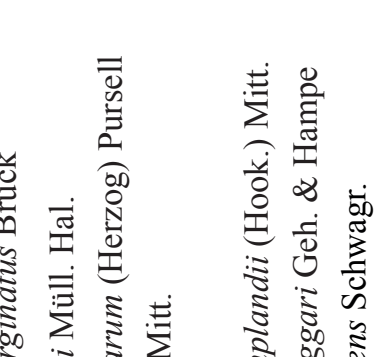

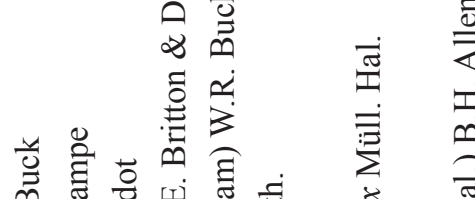

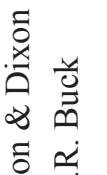

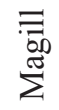

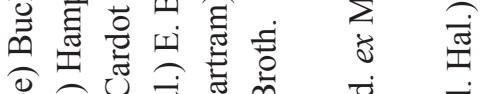

葉

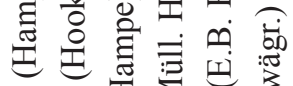

गं

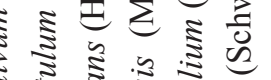

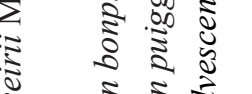

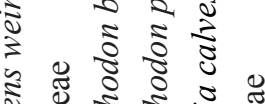

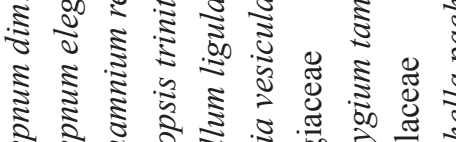

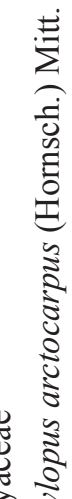

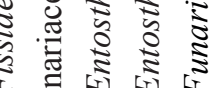

旅

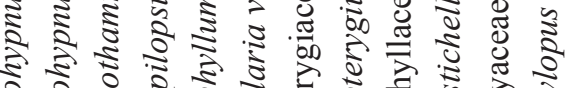

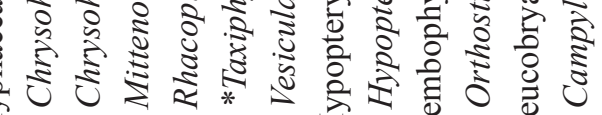




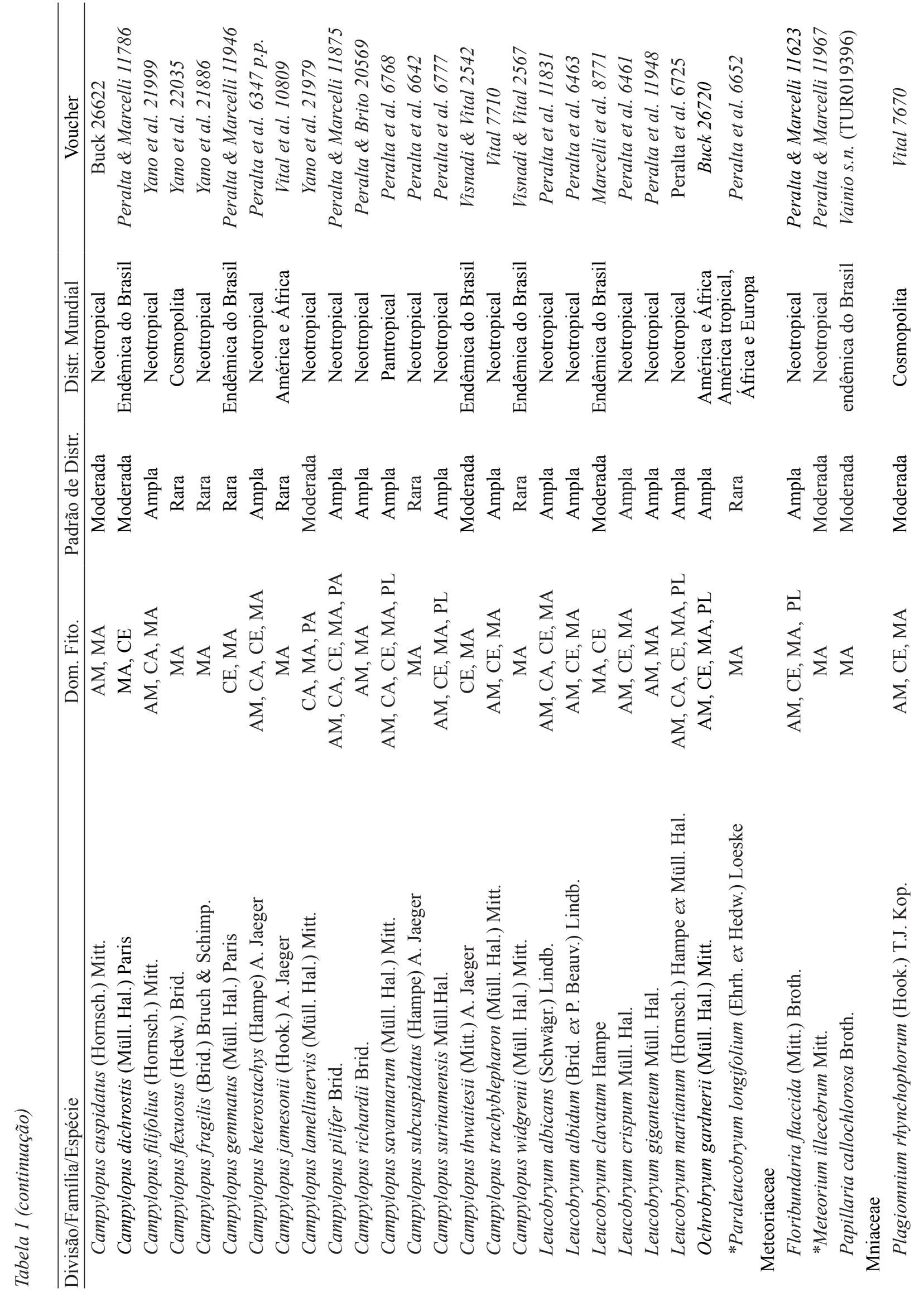




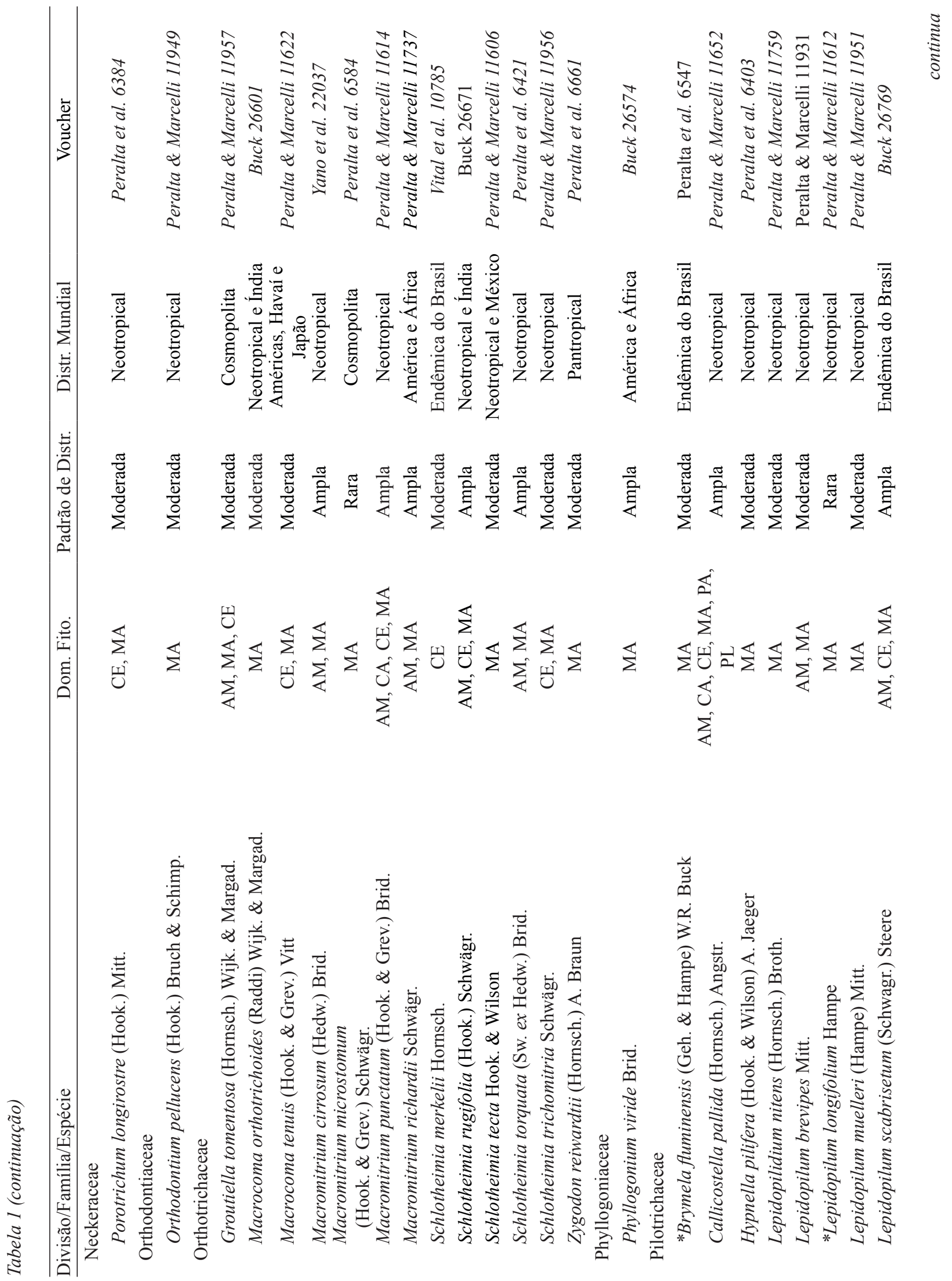




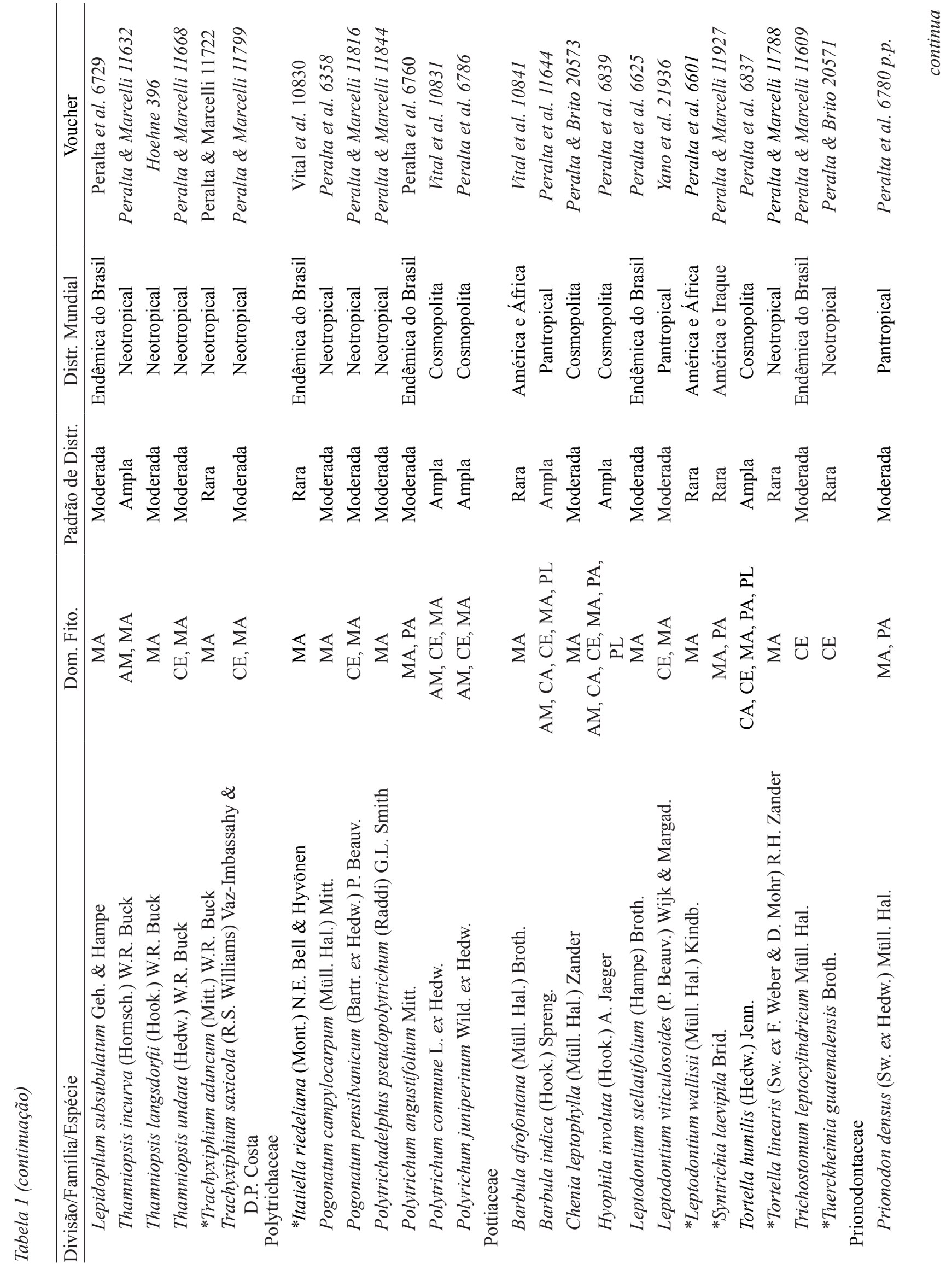




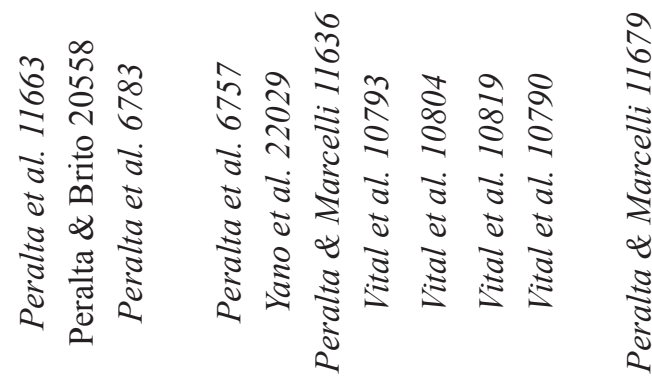

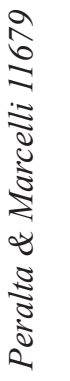

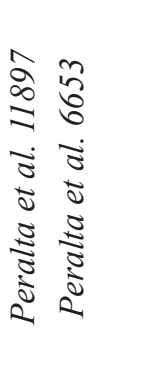

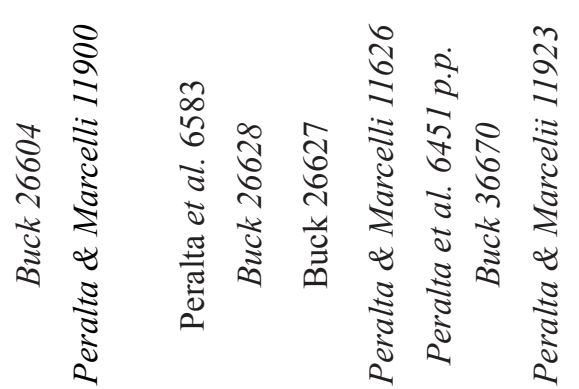

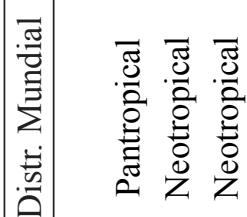

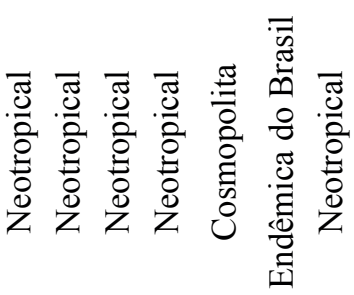

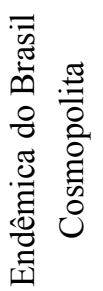

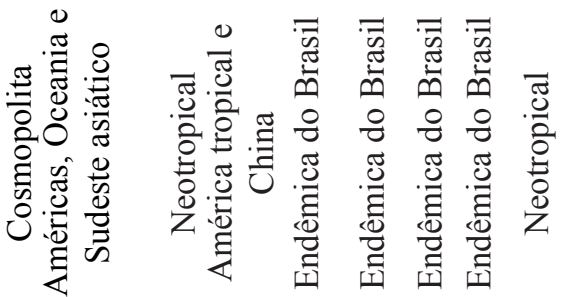

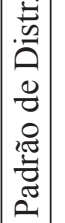

$\frac{\pi}{\frac{\pi}{\pi}}$

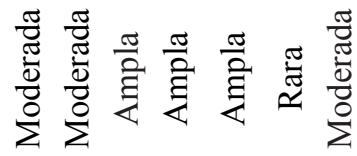

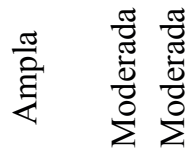

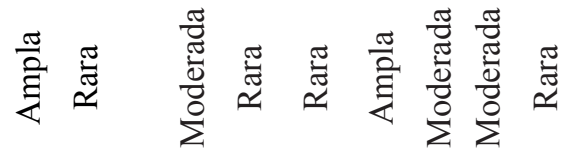

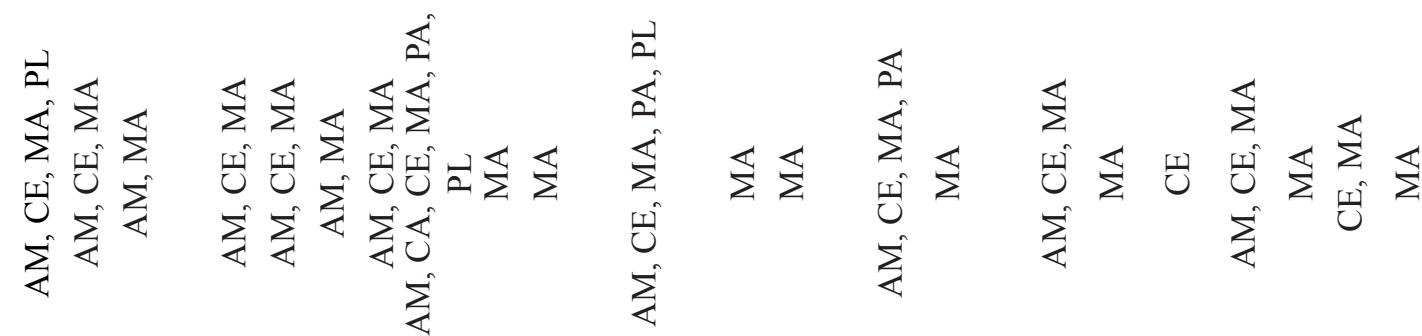

\section{定

$$
\sum
$$

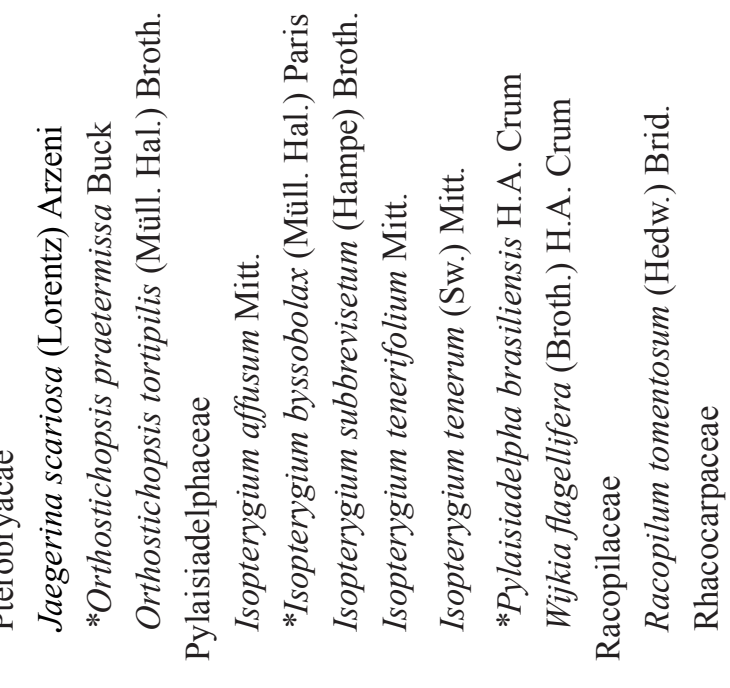

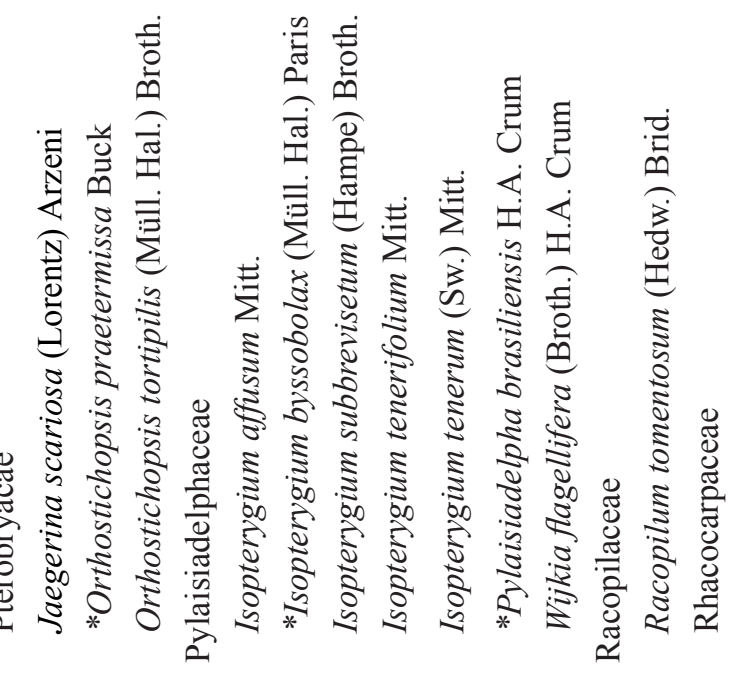

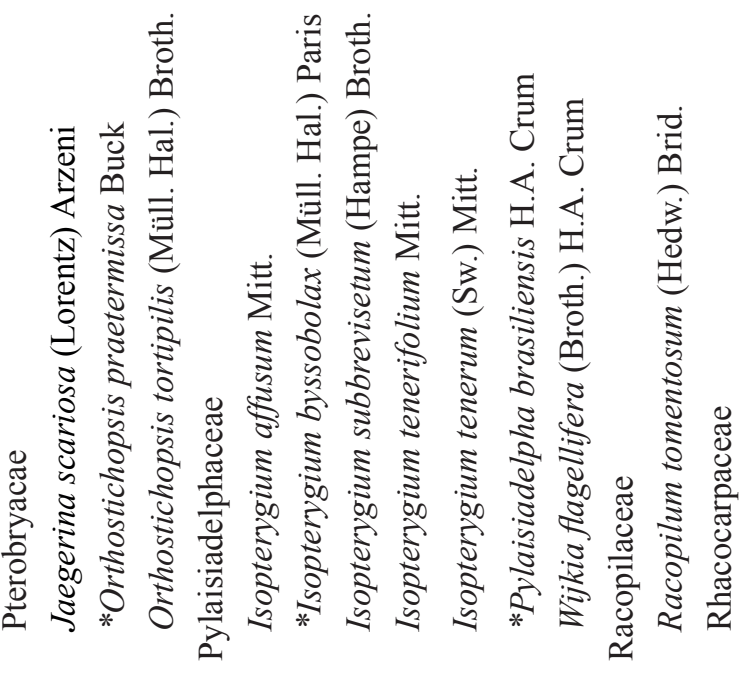

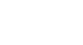

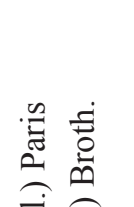

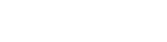

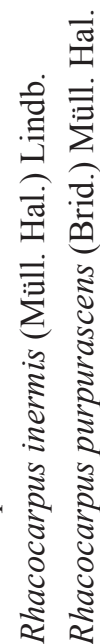

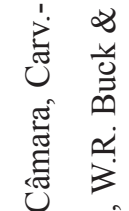

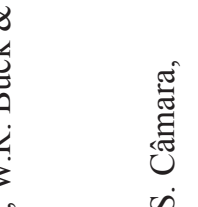

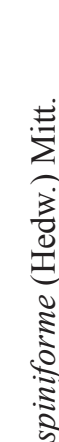

.

i

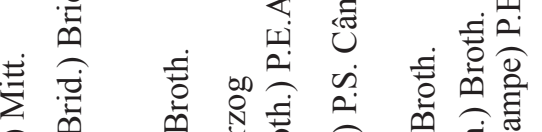

章

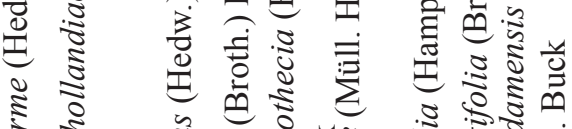

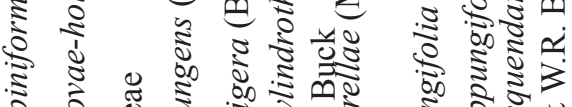

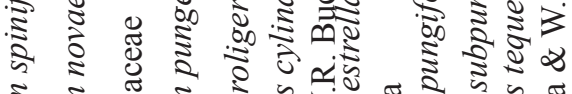

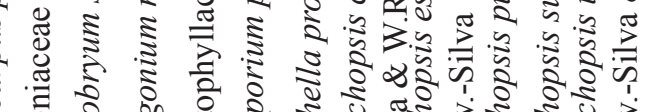

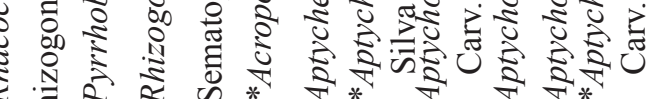




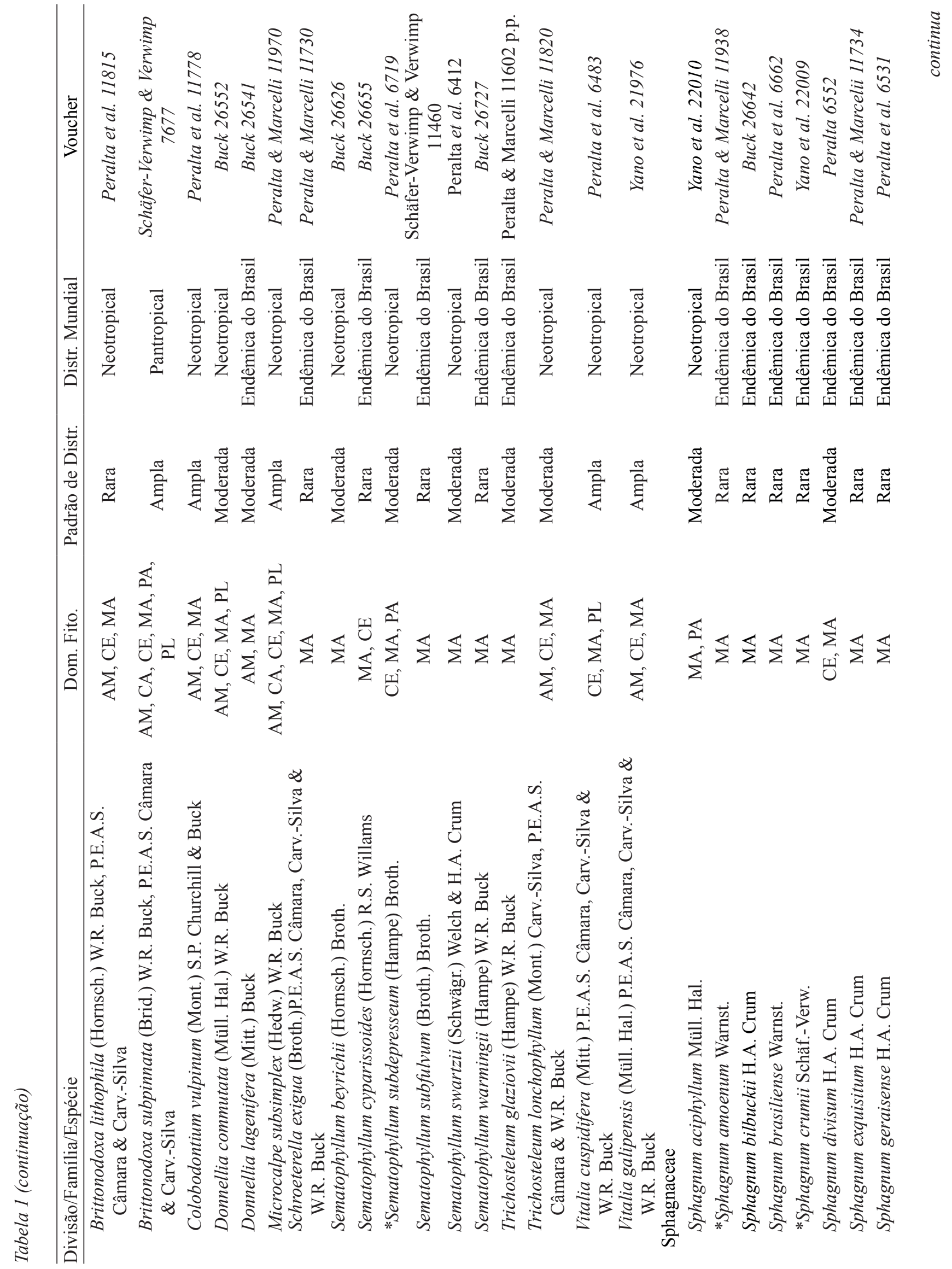




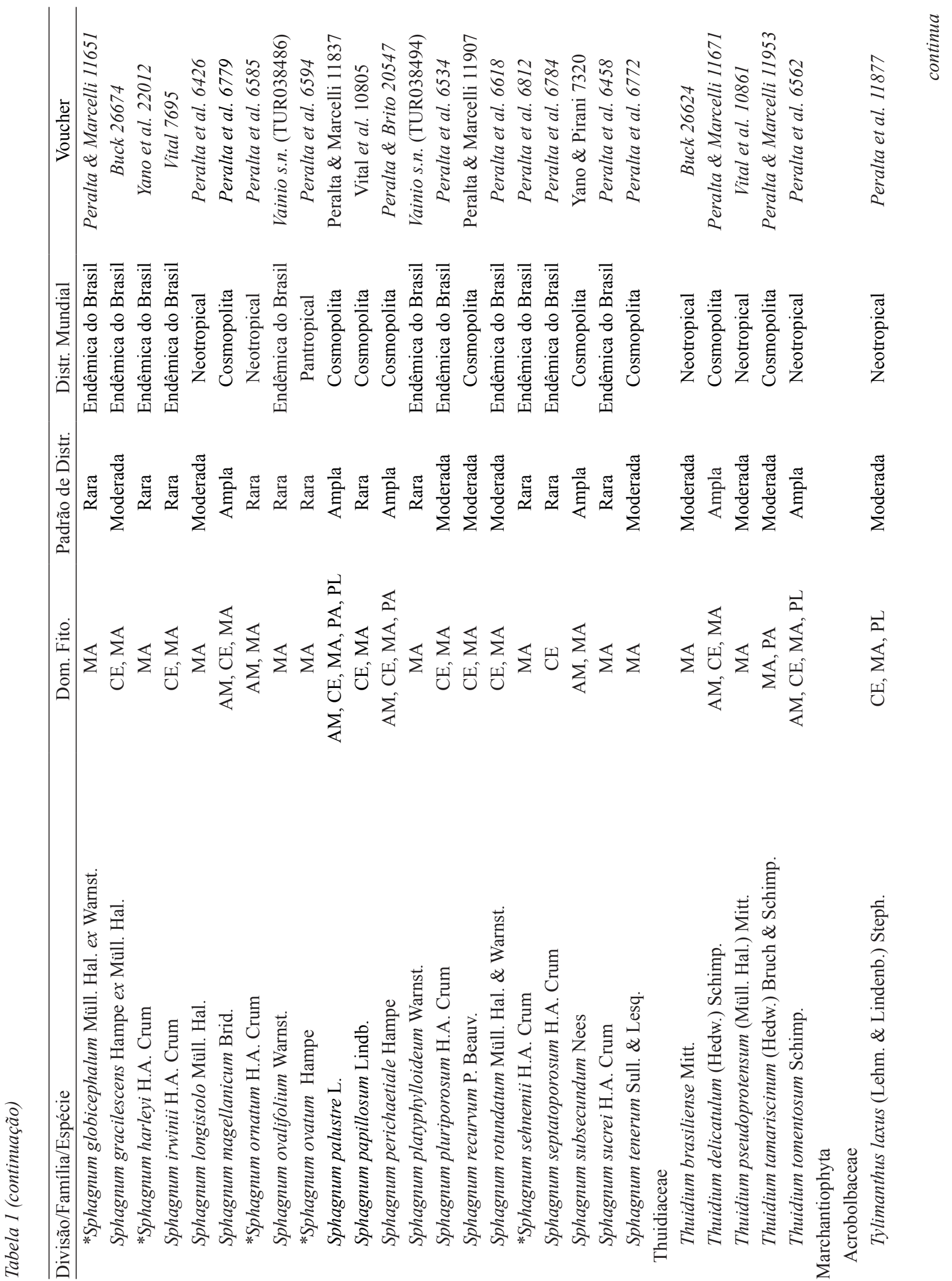




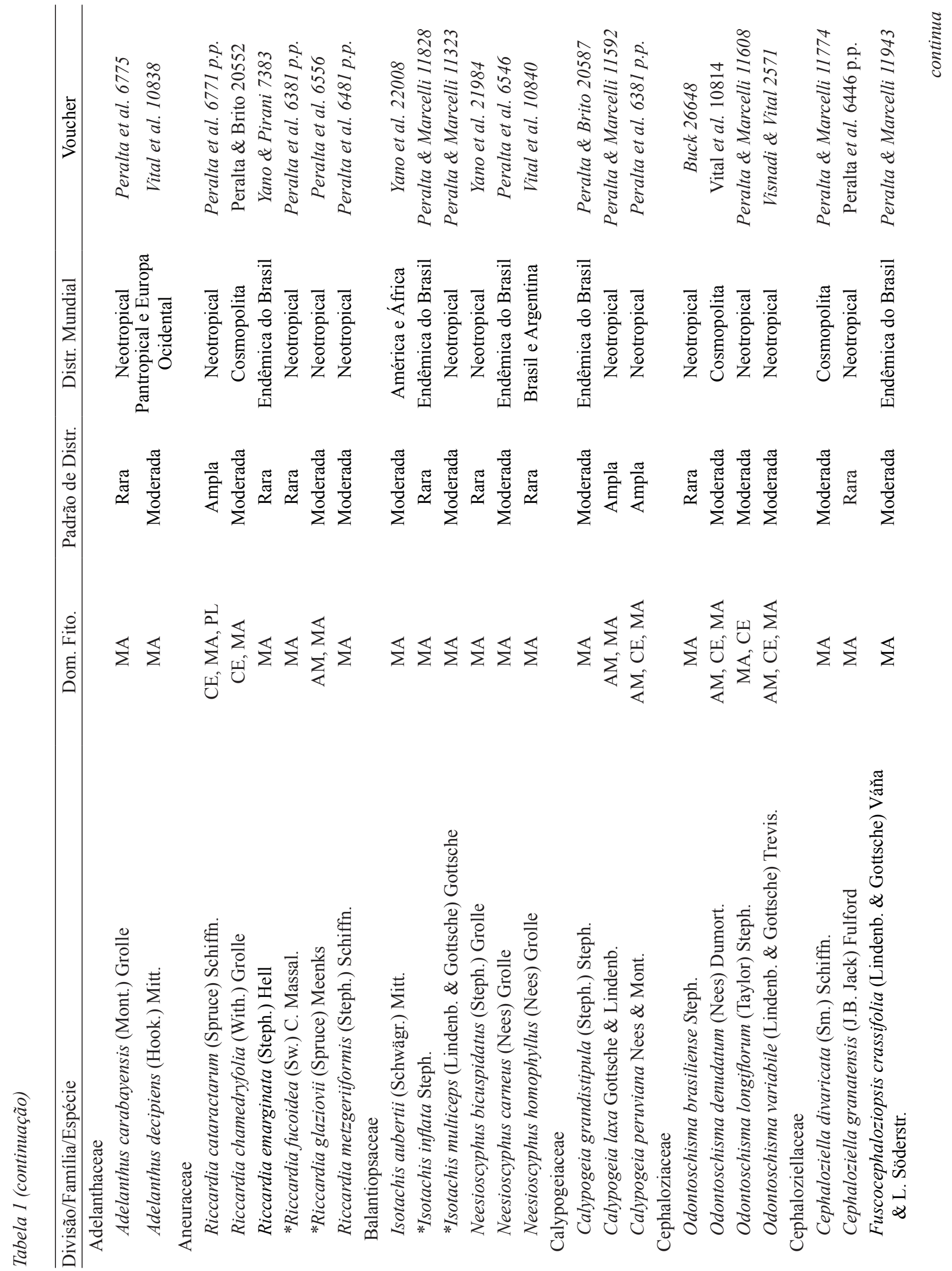




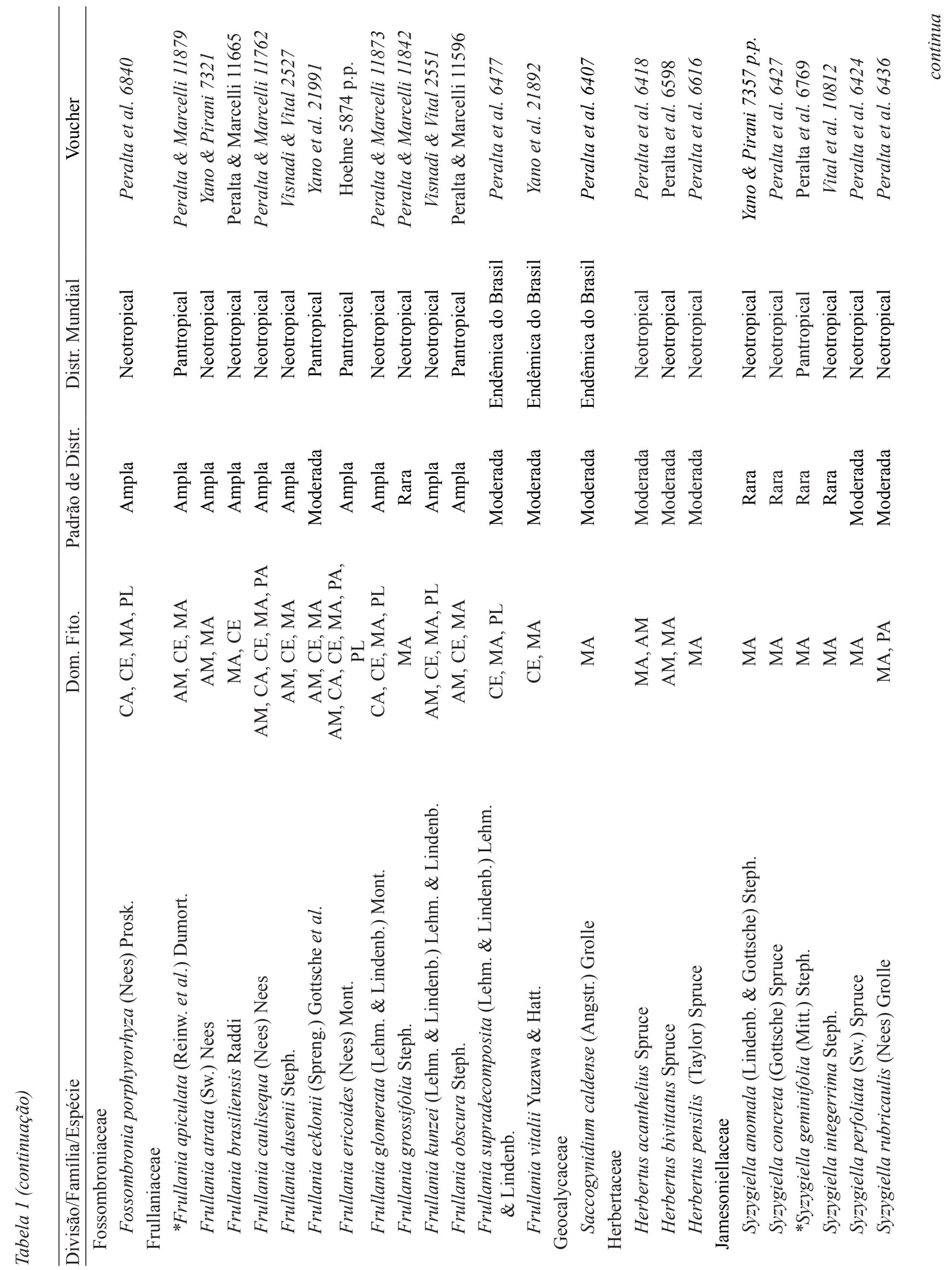




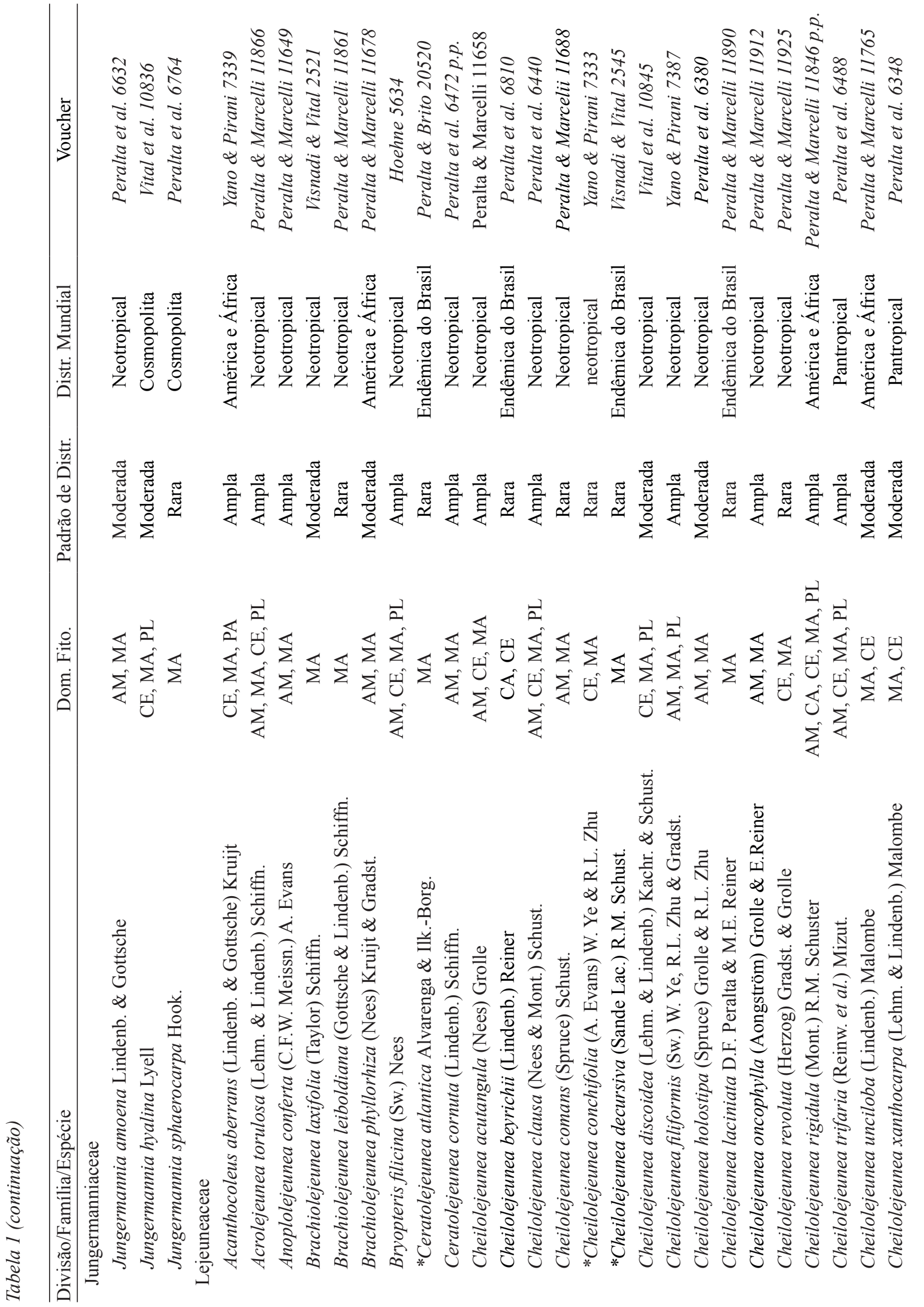




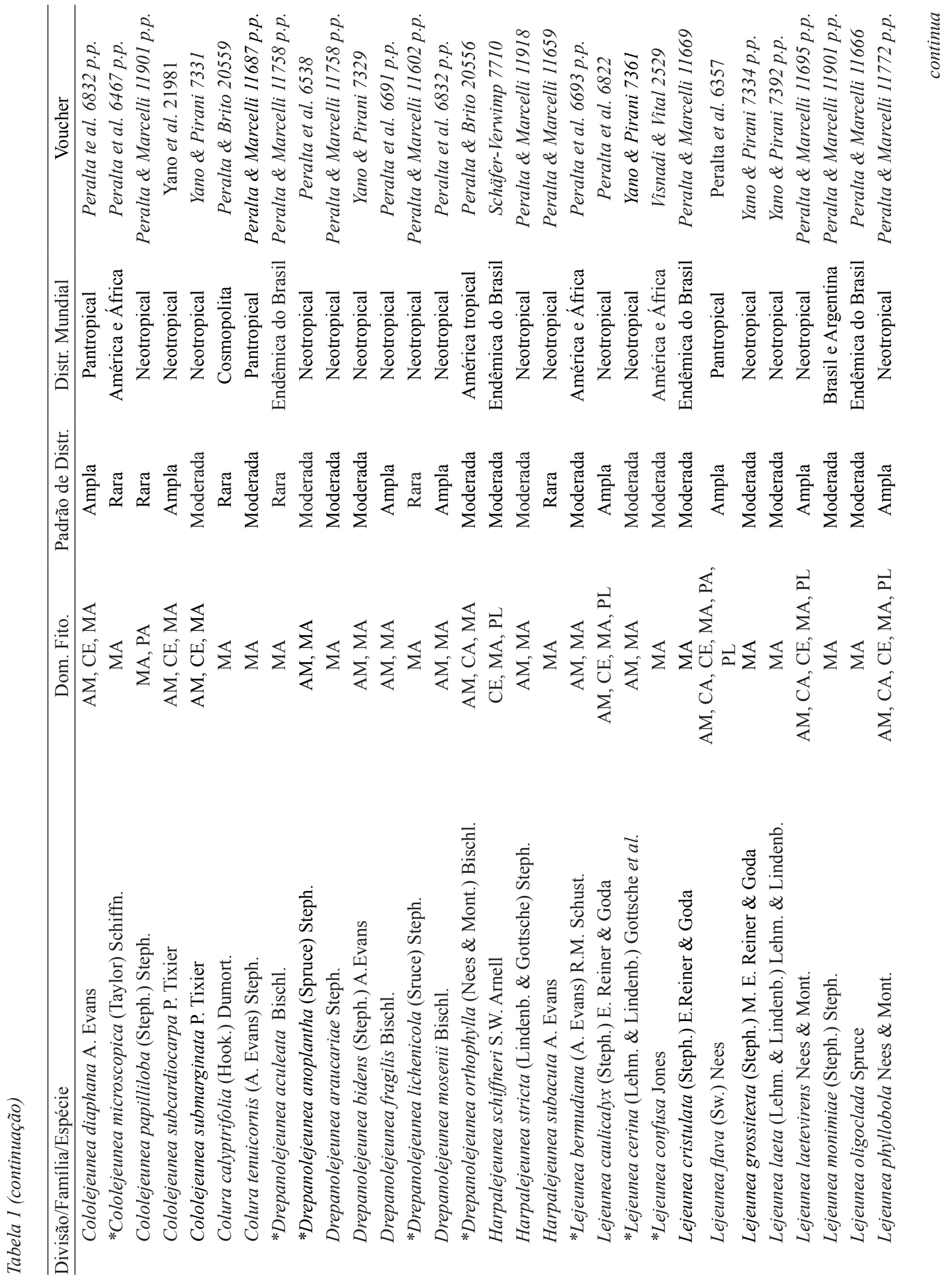




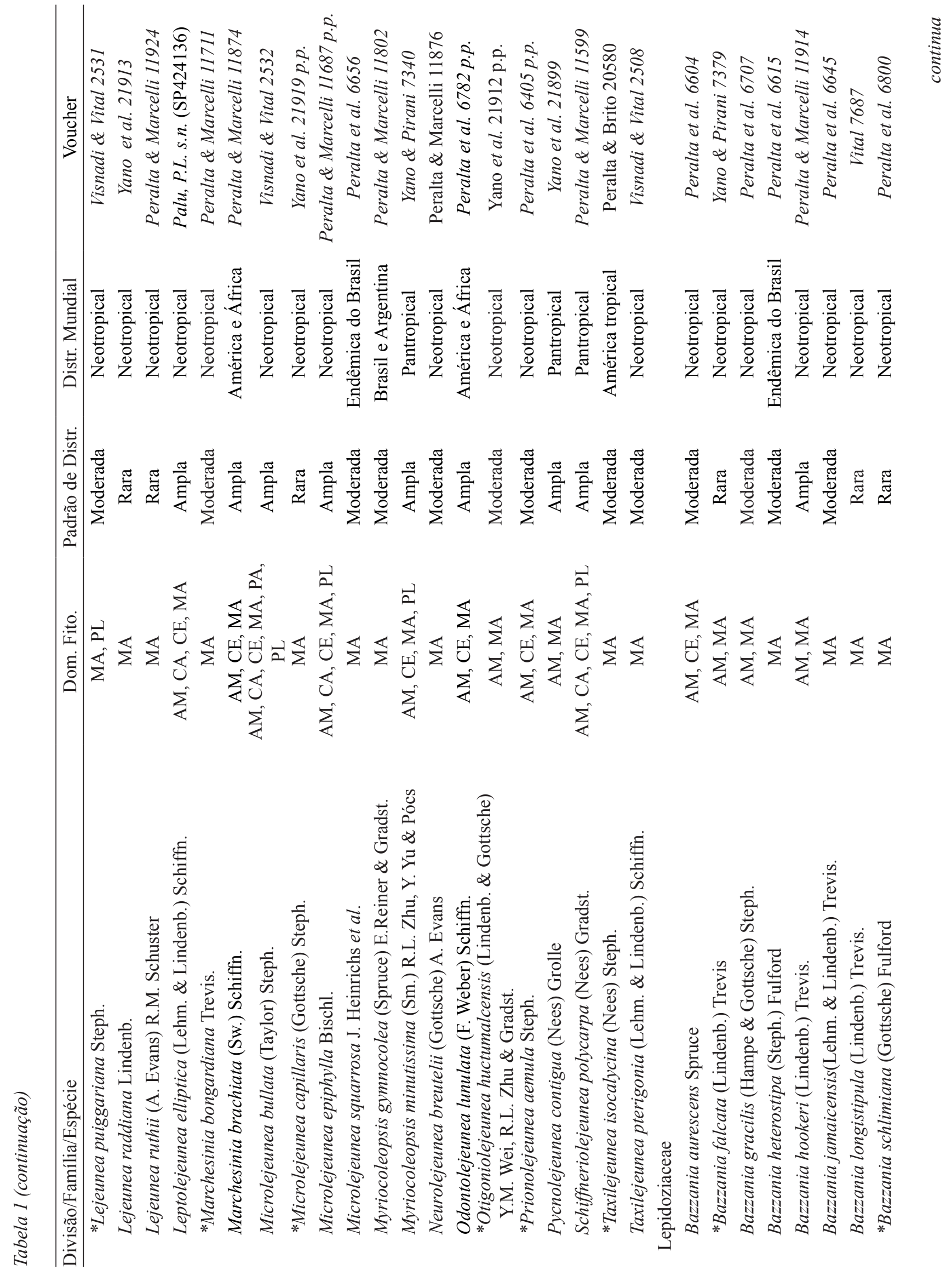




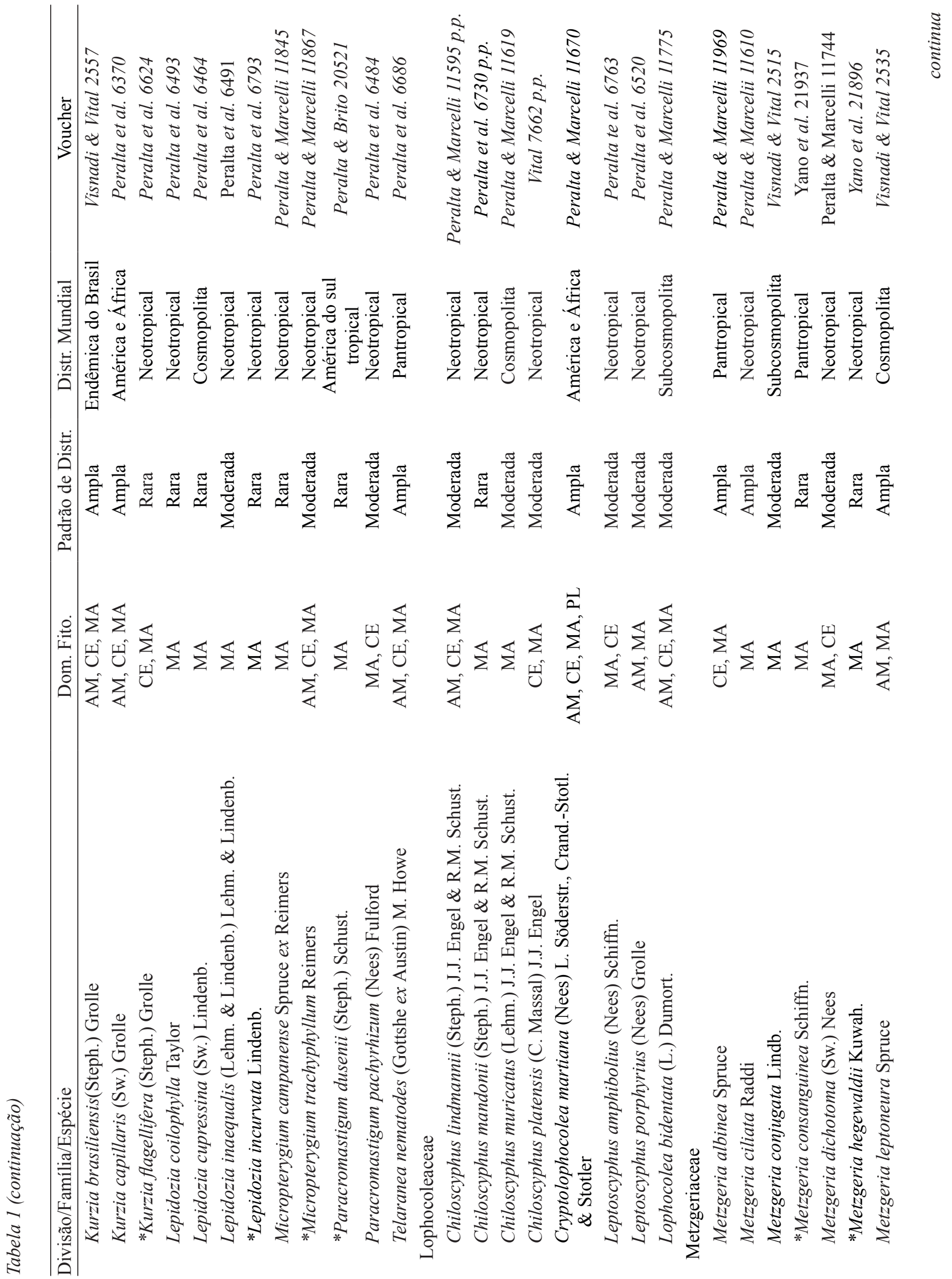




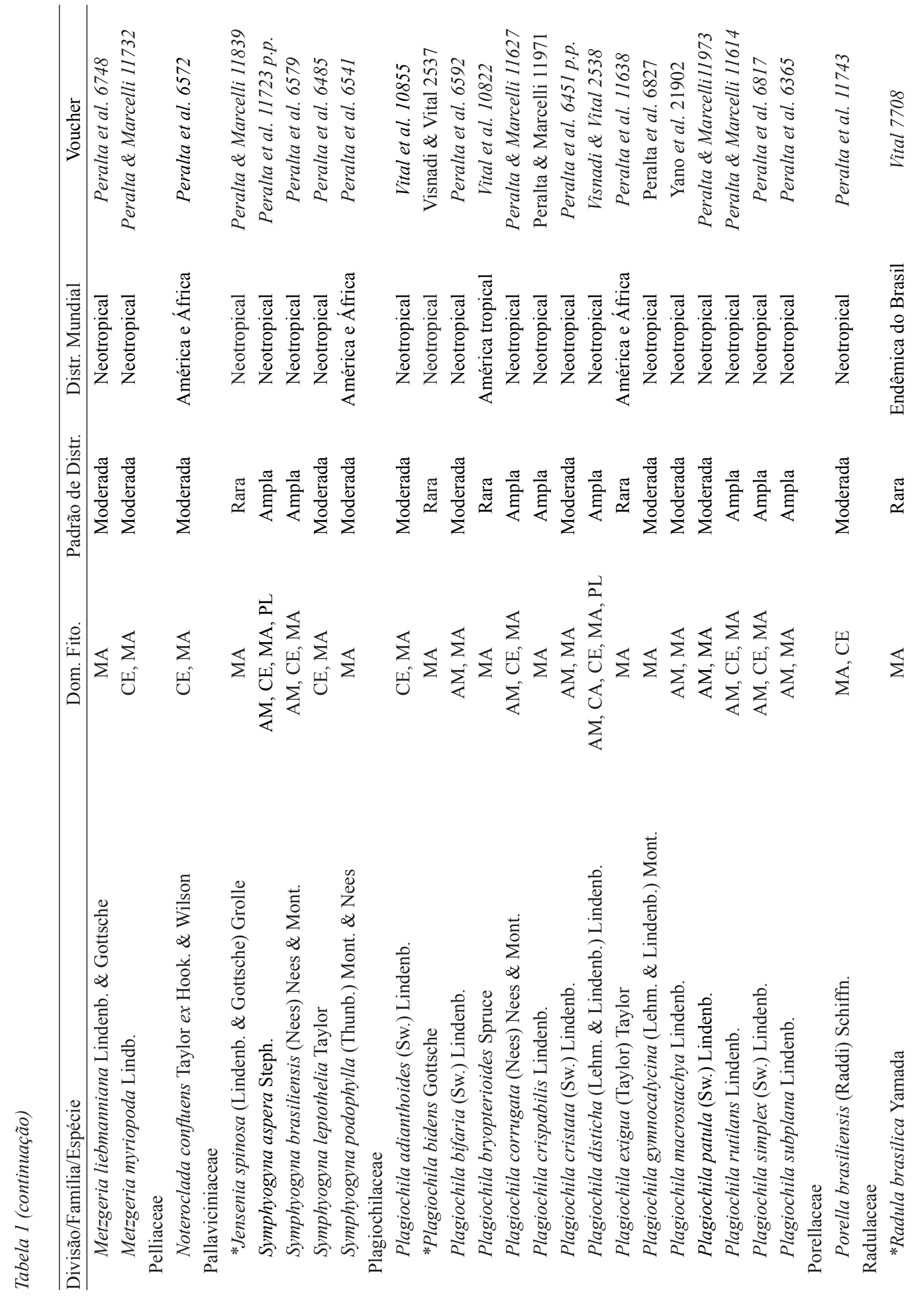




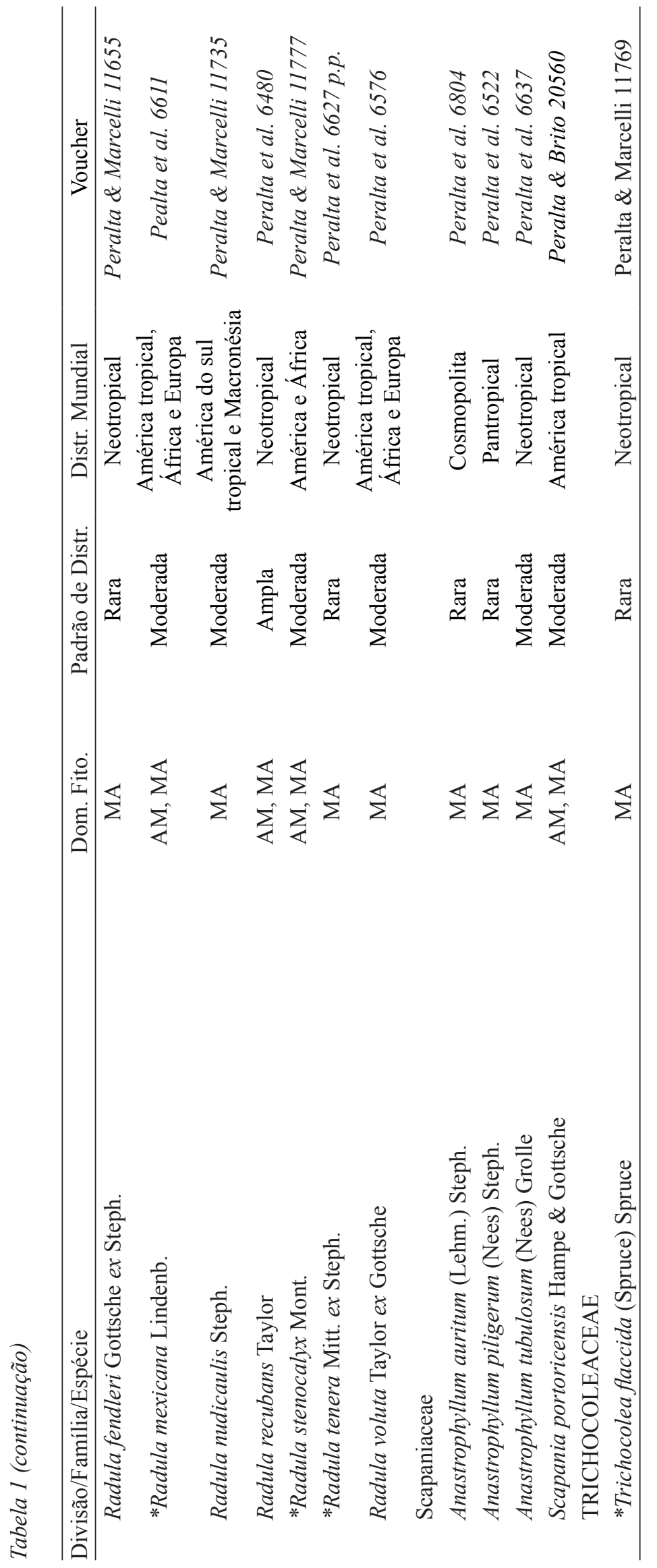


Tabela 2. Relação da distribuição e da riqueza de espécies encontradas na Reserva Particular Patrimônio Natural (RPPN) da Serra do Caraça em relação a outras escalas regionais. Os números entre parênteses representam a porcentagem relacionada com a riqueza encontrada na RPPN da Serra do Caraça.

Table 2. Relation of the distribution and of the species richness found in the Reserva Particular Patrimônio Natural (RPPN) da Serra do Caraça in relation to other regional scales. The numbers in parentheses represent the percentage related to the richness found at the RPPN da Serra do Caraça.

\begin{tabular}{lcc}
\hline Região & Riqueza de briófitas & Referências \\
\hline RPPN da Serra do Caraça & 439 & Carmo et al. presente estudo \\
Estado de Minas Gerais & $773(57 \%)$ & Flora do Brasil 2020 \\
Brasil & $1544(28 \%)$ & Flora do Brasil 2020 \\
América Tropical & $3980(11 \%)$ & Gradstein et al. 2001 \\
\hline
\end{tabular}

gêneros e encontradas em todas as fitofisionomias brasileiras (Flora do Brasil 2020). Nesse trabalho a família Lejeuneaceae foi a que apresentou a maior riqueza de espécies ( 75 espécies), bem como de novas ocorrências (17 espécies) (tabela 1), isso também foi observado em outros estudos realizados em áreas de elevadas altitudes no Estado de Minas Gerais (Yano \& Carvalho 1995, Yano \& Peralta 2009, Yano \& Peralta 2011a, b, Luizi-Ponzo et al. 2013, Carmo \& Peralta 2016, Carmo \& Peralta 2017). A família Lejeuneaceae possui uma origem evolutiva recente e um processo de diversificação independente que resultaram em uma ampla variação morfológica e de ocupação de substratos (Groth-Malonek et al. 2004), além disso, essa família também é bem representada em áreas de clima úmido, onde podem crescer em galhos, troncos de árvores vivas ou caídas, rochas, solos e folhas vivas (Gradstein et al. 2001), características que podem ter contribuído para sua elevada diversidade na região da RPPN da Serra do Caraça.

Para os antóceros, foram encontradas duas espécies que até então não tinham sido registradas para o Estado de Minas Gerais, Nothoceros minarum (Ness) J.C. Villarreal e Phymatoceros bulbiculosus (Broth.) Stotler et al., sendo representantes das famílias Dendrocerotaceae e Phymatocerotaceae, respectivamente (tabela 1 ).

Comparando a área da RPPN da Serra do Caraça com outras regiões no Estado de Minas Gerais, também podemos encontrar a riqueza de musgos sendo superior à de hepáticas (Yano \& Carvalho 1995, Yano \& Peralta 2009, Yano \& Peralta 2011a, b, Luizi-Ponzo et al. 2013, Carmo \& Peralta 2016, Carmo \& Peralta 2017). Os musgos são mais resistentes à dessecação e apresentam estruturas morfológicas mais complexas e diversificadas do que as hepáticas (Goffinet et al. 2009), sendo essas características responsáveis por uma capacidade melhor de ocupação nos substratos em ambientes mais secos e expostos, como o caso dos diversos campos rupestres existentes dentro da RPPN da Serra do Caraça. Esse fato também pode ser corroborado com os resultados encontrados nos campos rupestres da Chapada Diamantina, que também fazem parte da Cadeia do Espinhaço, no Estado da Bahia (Bastos et al. 2000, Valente et al. 2013, Valente et al. 2017) e na Serra da Canastra no Estado de Minas Gerais (Carmo \& Peralta 2016, Carmo \& Peralta 2017).

Em relação ao padrão de distribuição das espécies encontradas na RPPN da Serra do Caraça com o Brasil, observamos que 177 espécies (40\%) apresentaram uma distribuição considerada moderada, ou seja, ocorriam de cinco a nove estados brasileiros, enquanto para uma distribuição ampla foram encontradas 136 espécies (31\%) e 126 espécies (29\%) apresentaram uma distribuição rara ou restrita (tabela 1). Quando aumentamos a escala da distribuição geográfica para um nível mais global, observamos a predominância de espécies neotropicais, com 231 espécies (53\%) e entre as briófitas endêmicas do Brasil, com 74 espécies (17\%) (tabela 1). Foram encontradas ao todo 80 espécies (18\%) como novas ocorrências para o Estado de Minas Gerais, das quais 55 (68\%) apresentaram distribuição rara pelo país, 25 (31\%) distribuição moderada e apenas uma espécie com uma distribuição ampla, representando a divisão das hepáticas, Frullania apiculata (Reinw. et al.) Dumort. (tabela 1). Esses dados nos revelam a importância dos trabalhos de levantamento florístico para o conhecimento da distribuição geográfica das espécies e a representatividade do Brasil para a diversidade de briófitas no Neotrópico.

A região da RPPN da Serra do Caraça está localizada entre os domínios fitogeográficos da Mata 
Atlântica e do Cerrado, caracterizando-se assim como uma zona de transição ou um ecótono (Costa et al. 2011). Sendo assim, foi possível encontrar espécies consideradas endêmicas tanto da Mata Atlântica, quanto do Cerrado como as espécies Campylopus dichrostis (Müll. Hal.) Paris, Itatiella riedeliana (Mont.) N.E. Bell \& Hyvönen e Leucobryum clavatum Hampe. Conforme os resultados desse estudo, 430 (98\%) das espécies encontradas ocorrem na Mata Atlântica, sendo que destas, 178 (41\%) foram registradas exclusivamente para o domínio da Mata Atlântica, enquanto para o Cerrado, 195 (44\%) espécies estão distribuídas nesse domínio fitogeográfico, porém com apenas cinco exclusivas (tabela 1), ou seja, podemos dizer que as características climáticas encontradas na RPPN da Serra do Caraça são similares às encontradas na Mata Atlântica. Tanto a Mata Atlântica, quanto o Cerrado, são considerados hotspots mundiais, logo a manutenção e preservação da RPPN da Serra do Caraça para a conservação da diversidade de briófitas é de fundamental importância.

Os dados apresentados nesse trabalho de levantamento florístico para a RPPN da Serra do Caraça acrescentaram relevantes informações sobre a diversidade, ocorrência e o padrão de distribuição geográfica das espécies de briófitas na RPPN da Serra do Caraça e nos domínios fitogeográficos brasileiros. Além disso, esse trabalho também apresentou um número significativo de espécies endêmicas brasileiras que ainda não tinham sido registradas, coletou mais amostras de espécies que só eram então conhecidas pelo seu material-tipo e forneceu novas ocorrências para o Estado de Minas Gerais, o que revela a importância dessa unidade de conservação para a proteção da biodiversidade de briófitas. Portanto, como observações complementares, esse trabalho ressaltou a importância dos trabalhos de inventários florísticos para o conhecimento da diversidade brasileira e estimula a necessidade de estudos com briófitas em outras áreas científicas como a ecologia, fitogeografia e diversidade genética para ampliarmos o conhecimento da relação desses organismos com o ambiente que ocupam.

\section{Agradecimentos}

Ao Instituto de Botânica de São Paulo (IBt) e ao Núcleo de Pesquisa em Briologia por fornecerem a assistência e estrutura necessária para a realização desse trabalho. À organização e administração da Reserva Particular do Patrimônio Natural da Serra do Caraça pela hospedagem.

\section{Literatura citada}

Ballejos, J. \& Bastos, C.J.P. 2009. Musgos Pleurocárpicos do Parque Estadual das Sete Passagens, Miguel Calmon, Bahia, Brasil. Hoehnea 36: 479-495.

Bastos, C.J.P., Yano, O \& Vilas Bôas-Bastos, S.B. 2000. Briófitas de Campos rupestres da Chapada Diamantina, Estado da Bahia, Brasil. Revista Brasileira de Botânica 23: 357-368.

Bordin, J. \& Yano, O. 2013. Fissidentaceae (Bryophyta) do Brasil. Boletim do Instituto de Botânica 22: 1-72.

Buck, W.R. 1998. Pleurocarpous Mosses of the West Indies. Memoirs of The New York Botanical Garden 1: 1-401.

Carmo, D.M. \& Peralta, D.F. 2016. Survey of bryophytes in Serra da Canastra National Park, Minas Gerais, Brazil. Acta Botanica Brasilica 30: 254-265.

Carmo, D.M. \& Peralta, D.F. 2017. Morpho-ecological characterization and composition of rocky fields bryophytes in Brazilian Cerrado. Boletín Sociedad Argentina de Botánica 52: 265-276.

Carvalho-Silva, M., Stech, M., Soares-Silva, L.H., Buck, W.R., Wickett, N.J., Liu, Y., \& Câmara, P.E.A.S. 2017. A molecular phylogeny of the Sematophyllaceae s.l. (Hypnales) based on plastid, mitochondrial and nuclear markers, and its taxonomic implications. Taxon 66: 811-831.

Câmara, P.E.A.S. 2008a. Musgos pleurocárpicos das matas de galeria da Reserva Ecológica do IBGE, RECOR, Distrito Federal, Brasil. Acta Botanica Brasilica 22: 573-581.

Câmara, P.E.A.S. 2008b. Musgos acrocárpicos das Matas de Galeria da Reserva Ecológica do IBGE, RECOR, Distrito Federal, Brasil. Acta Botanica Brasilica 22: 1027-1035.

Câmara, P.E.A.S. \& Costa, D.P. 2006. Hepáticas e antóceros das matas de galeria da Reserva Ecológica do IBGE, RECOR, Distrito Federal, Brasil. Hoehnea 33: 79-87.

Costa, D.P., Pôrto, K.C., Luizi-Ponzo, A.P., Ilkiu-Borges, A.L., Bastos, C.J.P., Câmara, P.E.A.S., Peralta, D.F., Bôas-Bastos, S.B.V., Imbassahy, C.A.A., Henriques, D.K., Gomes, H.C.S., Rocha, L.M., Santos, N.D., Siviero, T. S., Vaz-Imbassahy, T.F. \& Churchill, S.P. 2011. Synopsis of the Brazilian moss flora: checklist, distribution and conservation. Nova Hedwigia 93: 277-334.

Couto Junior, A.F.C., Souza, V.V., Junior, O.A.C., Martins, E.S., Santana, O.A., Freitas, L.F \& Gomes, R.A.T. 2010. Integração de parâmetros morfométricos e imagem aster para a delimitação das fitofisionomias da Serra da Canastra, Parque Nacional da Serra da Canastra, MG. Revista Brasileira de Geomorfologia 11: 57-68. 
Crandall-Stotler, B., Stotler, R.E. \& Long, D.G. 2009. Morphology and classification of the Marchantiophyta. In: B. Goffinet \& A.J. Shaw Bryophyte Biology. 2 ed. Cambdrige University Press, pp. 1-54.

Ferreira, M.B., D'Assumpção, W.R.C. \& Magalhães, G.M. 1977. Nova Contribuição para o Conhecimento da Vegetação da Cadeia do Espinhaço ou Serra Geral (Maciço do Caraça). Oreades 10:49-66.

Flora do Brasil 2020 em construção. 2017. Jardim Botânico do Rio de Janeiro. Disponível em http:// floradobrasil.jbrj.gov.br (acesso em 23-III-2017).

Forzza, R.C., Leitman, P.M., Costa, A.F., Carvalho, J.R., Peixoto, A.L., Walter, B.M.T., Bicudo, C., Zappi, D., Costa, D.P., Lleras, E., Martinelli, G., Lima, H.C., Prado, J., Stehmann, J.R., Baumgratz, J.F.A., Pirani, J.R., Sylvestre, L., Maia, L.C., Lohmann, L.G., Queiroz, L.P., Silveira, M., Coelho, M.N., Mamede, M.C., Bastos, M.N.C., Morin, M.P., Barbosa, M.R., Menezes, M., Hopkins, M., Secco, R., Cavalcanti, T.B. \& Souza, V.C. 2010. Introdução. In: Lista de espécies da Flora do Brasil. Jardim Botânico do Rio de Janeiro. Vol. 1. Jardim Botânico do Rio de Janeiro.

Frahm, J.P. 1991. Dicranaceae: Campylopodioideae, Paraleucobryoideae. Flora Neotropica Monograph 54: 1-237.

Frey, W. \& Stech, M. 2009. Marchantiophyta, Bryophyta and Anthocerotophyta. In: W. Frey, M. Stech \& E., Fischer. Syllabus of plant families. Bryophytes and seedless Vascular Plants, v.13, pp. 1-419.

Giulietti, A.M. \& Pirani, J.R. 1988. Patterns of geographic distribution of some plant species from the Espinhaço Range, Minas Gerais and Bahia, Brazil. In: P.E. Vanzolini \& W.R. Heyer. Proceedings of a workshop on Neotropical distribution patterns. Academia Brasileira de Ciências, Rio de Janeiro, pp. 39-69.

Giulietti, A.M., Menezes, N.L., Pirani, J.R., Meguro, M. \& Wanderley, M.G.L. 1987. Flora da Serra do Cipó, Minas Gerais: caracterização e lista das espécies. Boletim de Botânica da Universidade de São Paulo 9: 1-151.

Giulietti, A.M., Pirani, J.R. \& Harley, R.M. 1997. Espinhaço Range region, eastern Brazil. In: S.D. Davis, V.H. Heywood, O. Herrera-MacBryde, J. Villa-Lobos \& A.C. Hamilton. Centres of plant diversity: a guide and strategy for their conservation. Information Press, Oxford, v.3, pp. 397-404.

Goffinet, B., Buck, W.R. \& Shaw, A.J. 2009. Morphology, anatomy and classification of the Bryophyta. In: B. Goffinet \& A.J. Shaw. 2 ed. Bryophyte Biology. Cambdrige University Press, pp. 56-138.

Gradstein, S.R. 2015. Annotated key to the species of Plagiochila (Marchantiophyta) from Brazil. Pesquisas, Botânica 67: 23-36.
Gradstein, S.R. \& Costa, D.P. 2003. The Hepaticae and Anthocerotae of Brazil. Memoirs of The New York Botanical Garden 87: 1-318.

Gradstein, S.R. \& Ilkiu-Borges, A.L. 2015. A taxonomic revision of the genus Odontoschisma (Marchantiophyta: Cephaloziaceae). Nova Hedwigia 100: 15-100.

Gradstein, S.R., Churchill, S.P. \& Salazar-Allen, N. 2001. Guide to the Bryophytes of Tropical America. Memoirs of The New York Botanical Garden 86: 1-577.

Groth-Malonek, M., Heinrichs, J., Schneider, H., \& Gradstein, S.R. 2004. Philogenetic relationships in the Lejeuneaceae (Hepaticae) inferred using ITS sequences of nuclear ribosomal DNA. Organisms, Diversity and Evolution 4: 51-57.

Kruijer, J.D. 2002. Hypopterygiaceae of the world. Blumea. Supplement 13: 1-388.

Luizi-Ponzo, A.P., Siviero, T.S., Amorim, E.T., Henriques, D.K., Rocha, L.M., Gomes, H.C.S., Paiva, L.A., Rodrigues, R.S., Silva, I.C., Silva, A.G.D., Ribeiro, G.C., Gomes, C.Q. \& Campeão, A.S. 2013. Briófitas do Parque Estadual do Ibitipoca no Herbário Prof. Leopoldo Kriegeer. In: R.C., Forzza, L.M., Neto, F.R.G., Salimena \& D. Zappi. Flora do Parque Estadual do Ibitipoca e seu entorno. 1 ed. UFJF, Juiz de Fora, v. 4, pp. 95-122.

Melo, E. 2000. Polygonaceae da Cadeia do Espinhaço, Brasil. Acta Botanica Brasilica 14: 273-300.

Morais, P.O. \& Lombardi, J.A. 2006. A Família Myrtaceae na Reserva Particular do Patrimônio Natural da Serra do Caraça, Catas Altas, Minas Gerais, Brasil. Lundiana 7: 3-32.

Rapini, A., Ribeiro, P.L., Lambert, S. \& Pirani, J.R. 2008. A flora dos campos rupestres da Cadeia do Espinhaço. Megadiversidade 4: 15-23.

Renzaglia, K.S., Villarreal, J.C. \& Duff, R.J. 2009. New insights into morphology, anatomy and systematics of hornworts. In: B. Goffinet \& A.J. Shaw. Bryophyte Biology. 2 ed. Cambdrige University Press, Cambridge, pp. 139-171.

Schofield, W.B. 1985. Introduction to Bryology. Macmillan Publisching Company, New York.

Sharp, A.J., Crum, H. \& Eckel, P. 1994. The Moss Flora of Mexico. Memoirs of The New York Botanical Garden 69: 1-1113.

Södeström, L., Crandall-Stotler, B., Stotler, R.E., Vána, J., Hagborg, A. \& Konrat, M.V. 2013a. Notes on Early Land Plants Today. 36. Generic treatment of Lophocoleaceae (Marchantiophyta). Phytotaxa 97: 36-43.

Södeström, L., Vána, J., Crandall-Stotler, B., Stotler, R.E., Hagborg, A. \& Konrat, M.V. 2013b. Notes on Early Land Plants Today. 43. New Combinations in Lophocoleaceae (Marchantiophyta). Phytotaxa 112: 18-32. 
Souza, R.V. \& Câmara, P.E.A.S. 2015. Survey of the bryophytes of a gallery forest in the National Park of Serra do Cipó, Minas Gerais, Brazil. Acta Botanica Brasilica 29: 24-29.

Valente, E.B. \& Pôrto, K.C. 2006. Hepáticas (Marchantiophyta) de um fragmento de Mata Atlântica na Serra da Jibóia, município de Santa Terezinha, BA, Brasil. Acta Botanica Brasilica 20: 433-441.

Valente, E.B., Pôrto, K.C. \& Bastos, C.J.P. 2011. Checklist of bryophytes of Chapada Diamantina, Bahia, Brazil. Boletim do Instituto de Botânica 21: 111-124.

Valente, E.B., Pôrto, K.C. \& Bastos, C.J.P. 2013. Species Richness and Distribution of bryophythes within different phytophysiognomies in the Chapada Diamantina region of Brazil. Acta Botanica Brasilica 27: 294-310.

Valente, E.B., Pôrto, K.C. \& Bastos, C.J.P. 2017. Habitat heterogeneity and diversity of bryophytes in campos rupestres. Acta Botanica Brasilica 31: 241-249.

Vasconcelos, M.F. 2011. O que são campos rupestres e campos de altitude nos topos de montanha do Leste do Brasil? Revista Brasileira de Botânica 34: 241-246.

Vaz, T.F. \& Costa, D.P. 2006a. Os gêneros Brymela, Callicostella, Crossomitrium, Cyclodictyon, Hookeriopsis, Hypnella e Trachyxiphyum (Pilotrichaceae, Bryophyta) no Estado do Rio de Janeiro, Brasil. Acta Botanica Brasilica 20: 955-973.
Vaz, T.F. \& Costa, D.P. 2006b. Os gêneros Lepidopilidium, Lepidopilum, Pilotrichum e Thamniopsis (Pilotrichaceae, Bryophyta) no Estado do Rio de Janeiro, Brasil. Acta Botanica Brasilica 20: 975-993.

Versieux, L.M., Wendt, T., Louzada, R.B. \& Wanderley, M.G.L. 2008. Bromeliaceae da Cadeia do Espinhaço. Megadiversidade 4: 126-138.

Visnadi, S.R. 2002. Meteoriaceae (Bryophyta) da Mata Atlântica do estado de São Paulo. Hoehnea 29: 159-187.

Visnadi, S.R. 2006. Sematophyllaceae da Mata Atlântica do nordeste do Estado de São Paulo. Hoehnea 33: 455-484.

Yano, O. 2008. Catálogo de antóceros e hepáticas brasileiros: literatura original, basiônimo, localidadetipo e distribuição geográfica. Boletim do Instituto de Botânica 19: 1-110.

Yano, O. \& Carvalho, A.B. 1995. Briófitas da Serra da Piedade, Minas Gerais, Brasil. In: Anais do 9ํㅡㄹ Congresso da Sociedade Botânica de São Paulo, pp. 15-25.

Yano, O. \& Peralta, D.F. 2009. Flora de Grão-Mogol, Minas Gerais. Briófitas (Bryophyta e Marchantiophyta). Boletim de Botânica da Universidade de São Paulo 27: 1-26.

Yano, O. \& Peralta, D.F. 2011a. Bryophytes from Serra de São José, Tiradentes, Minas Gerais, Brasil. Boletim de Botânica da Universidade de São Paulo 21: 141-172.

Yano, O. \& Peralta, D.F. 2011b. Flora da Serra do Cipó, Minas Gerais: Briófitas (Anthocerotophyta, Bryophyta e Marchantiophyta). Boletim de Botânica da Universidade de São Paulo 29: 135-211. 